\title{
Living with migraine headache: A phenomenological study of women's experiences
}

Anthony R. Ramsey

West Virginia University

Follow this and additional works at: https://researchrepository.wvu.edu/etd

\section{Recommended Citation}

Ramsey, Anthony R., "Living with migraine headache: A phenomenological study of women's experiences" (2011). Graduate Theses, Dissertations, and Problem Reports. 3465.

https://researchrepository.wvu.edu/etd/3465

This Dissertation is protected by copyright and/or related rights. It has been brought to you by the The Research Repository @ WVU with permission from the rights-holder(s). You are free to use this Dissertation in any way that is permitted by the copyright and related rights legislation that applies to your use. For other uses you must obtain permission from the rights-holder(s) directly, unless additional rights are indicated by a Creative Commons license in the record and/ or on the work itself. This Dissertation has been accepted for inclusion in WVU Graduate Theses, Dissertations, and Problem Reports collection by an authorized administrator of The Research Repository @ WVU.

For more information, please contact researchrepository@mail.wvu.edu. 
Living with migraine headache: A phenomenological study of women's experiences

\author{
Anthony R. Ramsey \\ Dissertation submitted to the School of Nursing \\ at West Virginia University \\ in partial fulfillment of the requirements \\ for the degree of \\ Doctor of Philosophy \\ in \\ Nursing
}

Approved by

Margaret Burkhardt, $\mathrm{PhD}$, RN, Committee Chairperson

Joy Buck, PhD, RN

Theresa Burriss, $\mathrm{PhD}$

Alvita Nathaniel, $\mathrm{PhD}, \mathrm{RN}$

Mary Jane Smith, PhD, RN

Morgantown, West Virginia

2011

Keywords: Migraine headache, Suffering, Story Theory, Phenomenology 


\begin{abstract}
Living with migraine headache: A phenomenological study of women's experiences Anthony R. Ramsey
\end{abstract}

Multiple studies have addressed migraine headache in recent years. There is little research related to women's experiences of living with migraine headache. Researchers have explored migraine headache from a pathophysiological perspective and medical treatment perspective. Studies exploring what it is like for women to live with migraine headache on a day-to-day life basis have not been produced. This qualitative study explored the lived experience of eight women who had migraine headache. Participant stories were gathered and analyzed using the middle range story theory and the phenomenological approach described by van Manen. A structure of meaning of living with migraine headaches with seven interrelated core qualities emerged from this study. Living with migraine headache is: (a) recalling the significant experience that reshaped life; (b) experiencing self as vulnerable, with unmet expectations, unfulfilled relationships, and regrets; (c) being overcome by unrelenting, torturous pain magnified by intrusion from the outside world; (d) pushing through to hold self together to do what needs to be done, in spite of torturous pain; (e) surrendering to the compelling call to focus on self in order to relieve the torturous pain; (f) making the most of pain-free time to get on with life and navigating the aftermath of the headache experience; and (g) being on guard against an unpredictable attack and yet hopeful that it is possible to outsmart the next attack. The findings of this study suggest that women with migraine headache endure physical, emotional and spiritual suffering not identified in the current literature. Theoretical, practical, and educational implications are discussed. 


\section{DEDICATION}

Dedicated to my wife, Kim, my nephews, Steve and Madison, my parents Leona and Raymond, and my in-laws, Keturah and Henry.

A special dedication to the women living with migraine headache. 


\section{ACKNOWLEDGEMENTS}

I would like to acknowledge several people who assisted me along this journey. I would like to thank Dr. Margaret "Peggy" Burkhardt for the guidance you have provided throughout this dissertation process. I cannot thank you enough for the countless hours you have spent talking with me on the phone and over coffee at Tamarack. I am very grateful to my committee members, Dr. Joy Buck, Dr. Theresa Burriss, Dr. Alvita Nathaniel and Dr. Mary Jane Smith. I was blessed to assemble the most talented committee possible, and I thank you for all of the hard work and words of wisdom you have provided. Dr. Mary Jane Smith and Dr. Cindy Persily, thank you for believing in me and admitting me to West Virginia University. After meeting with you, I knew that I would attend the best School of Nursing in the country.

Thank you to the additional WVU PhD faculty I have had the pleasure of working with over the past six years including Dr. Larrabee, Dr. McCrone, Dr. Lunney, Dr. Shelton, and Dean Narsavage. Your classes and guidance assisted me to this point, and I am forever grateful for the learning you have provided. I would also like to thank Brandy Toothman and Dianne Griffith for keeping me on task with up to date information, and for assisting me with assembling documents for this study.

I wish to acknowledge my WVU friends who have stood side by side with me on this journey. Amy, Jen, Joyce, Margaret, Tina and Teri, you all are the best. I would not have made it this far without you to lean on. I am proud of your work and our friendship.

Last, but certainly not least, thank you to my friends and colleagues at Radford University, especially Theresa Burriss, Kim Carter, and Pam Moore. To my family, I am grateful for your understanding when I was away in Morgantown and too busy on the weekends to do other things. Your love and support is what got me through. 


\section{TABLE OF CONTENTS}

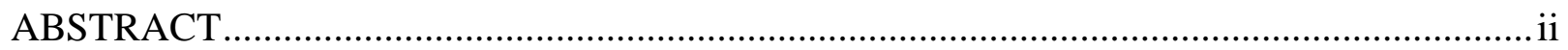

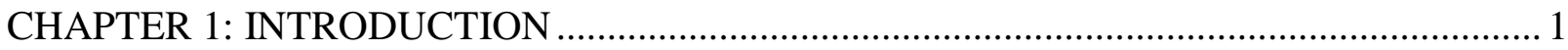

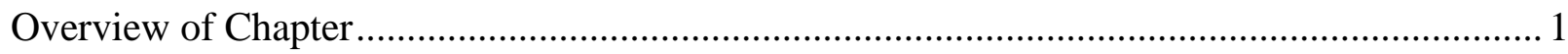

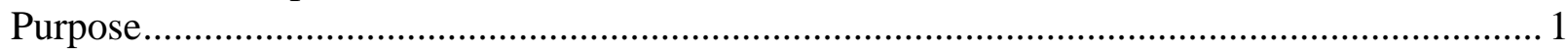

Definition of Migraine ……………………………

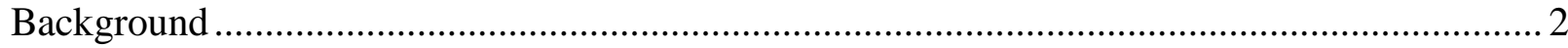

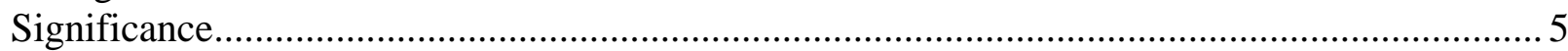

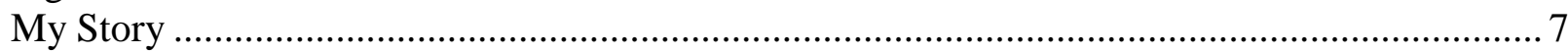

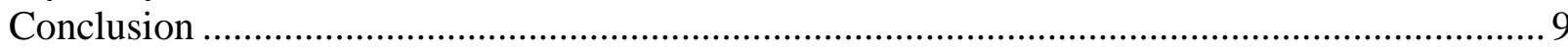

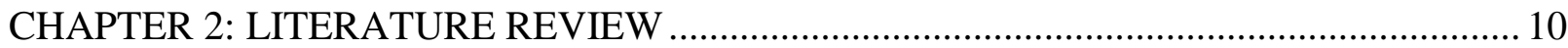

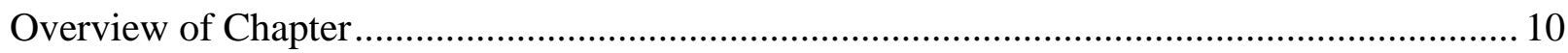

An Overview of the History of Migraine Headaches ............................................................. 10

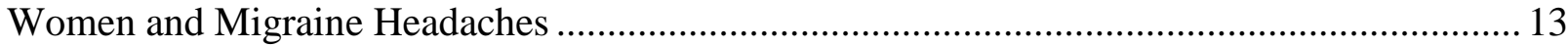

Migraine and Hormones .......................................................................................... 13

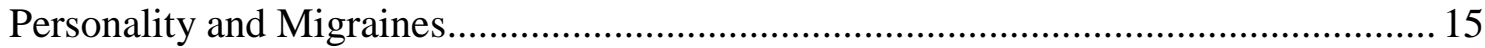

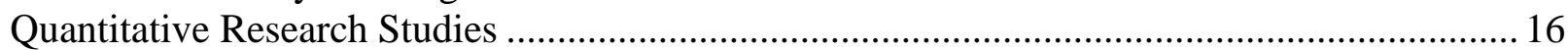

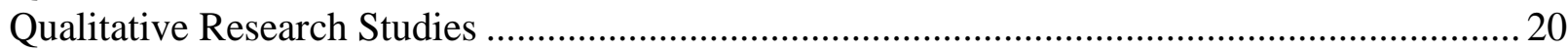

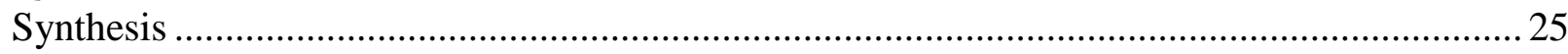

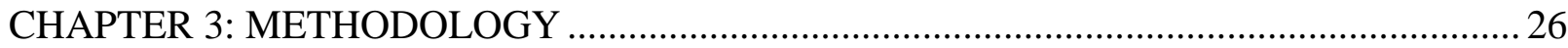

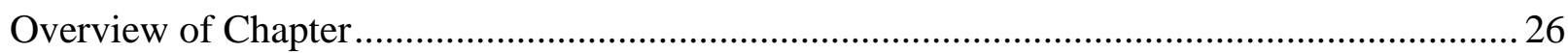

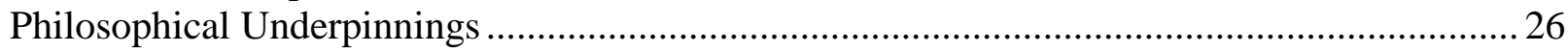

Phenomenology as a Philosophy and a Research Method ......................................................2 27

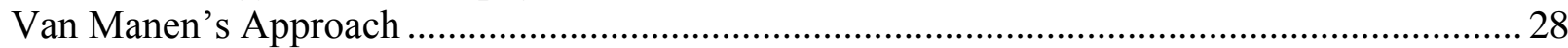

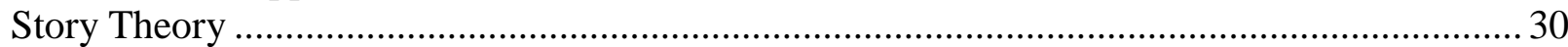

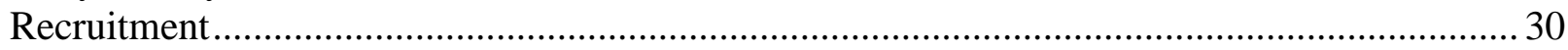

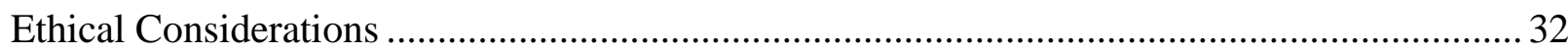

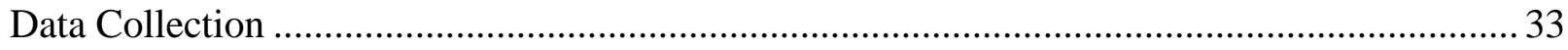

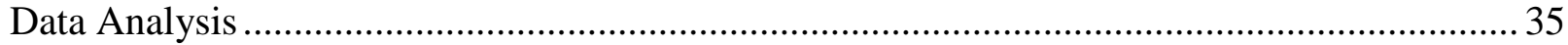

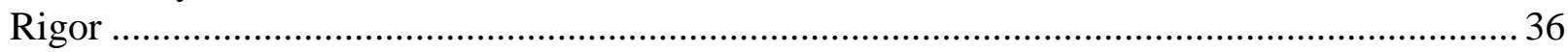

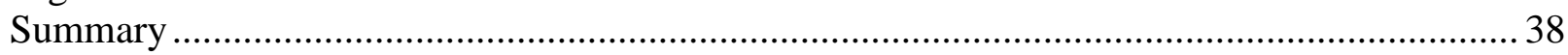

CHAPTER 4: PRESENTATION OF FINDINGS …………................................................... 39

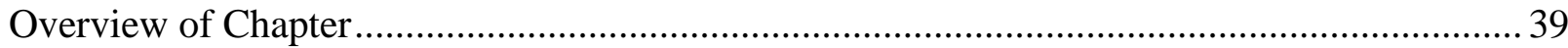

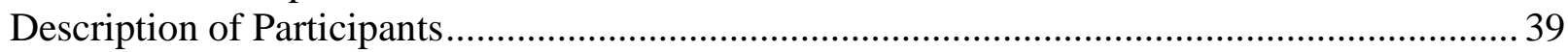

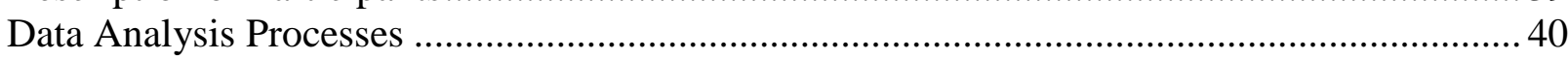

Turning to a phenomenon which seriously interests us and commits us to the world.... 40 Investigating experience as we live it rather than as we conceptualize it........................4 4

Reflecting on essential themes which characterize the phenomenon ............................... 41

Describing the phenomenon through the art of writing and rewriting............................42

Maintaining a strong and oriented nursing relation to the phenomenon ..........................4 43

Balancing the research context by considering parts and whole ..................................... 44 


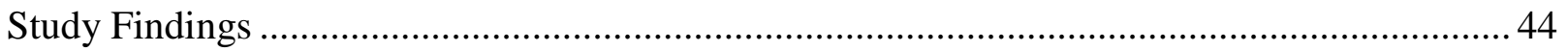

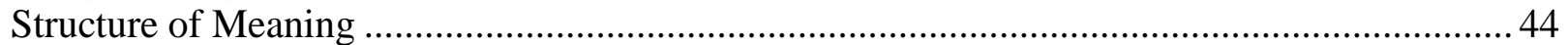

Recalling the significant experience that reshaped life.................................................45

Experiencing self as vulnerable, with unmet expectations, unfulfilled relationships, and

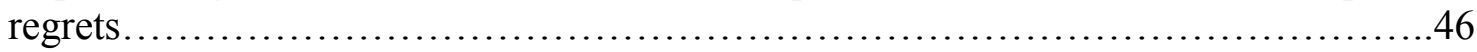

Being overcome by unrelenting, torturous pain magnified by intrusion from the outside

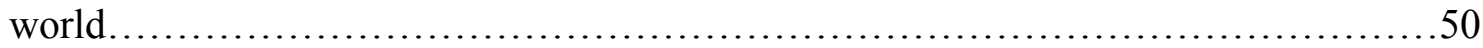

Pushing through to hold self together to do what needs to be done, in spite of torturous

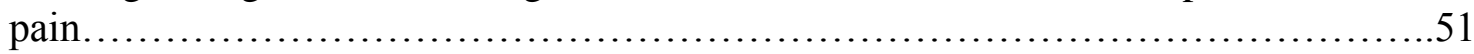

Surrendering to the compelling call to focus on self in order to relieve the torturous

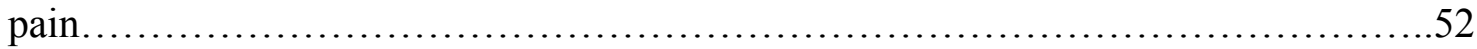

Making the most of pain-free time to get on with life and navigating the aftermath of the headache experience......................................................... 54

Being on guard against an unpredictable attack and yet hopeful that it is possible to

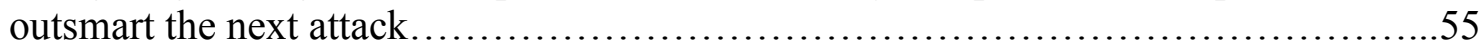

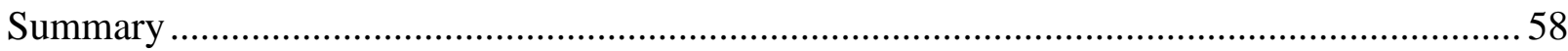

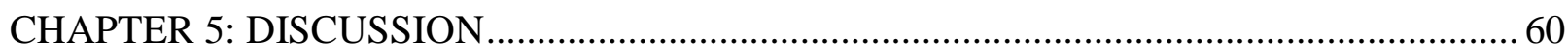

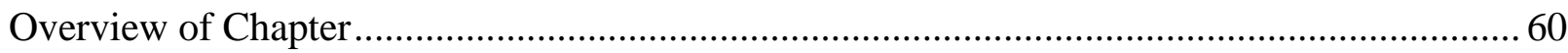

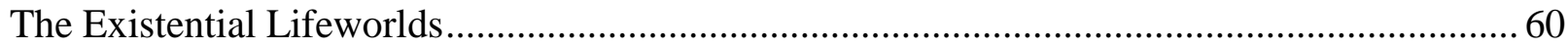

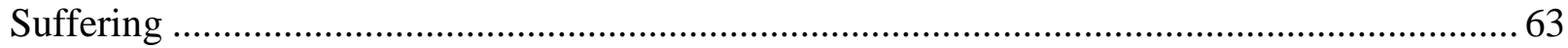

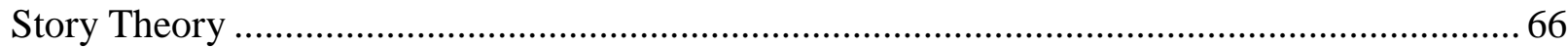

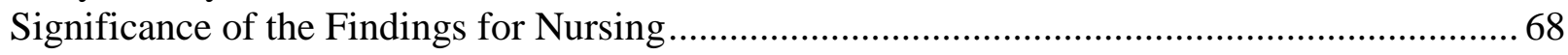

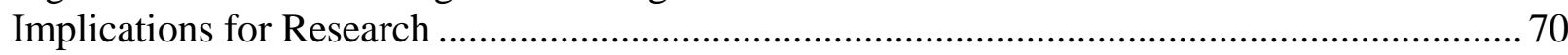

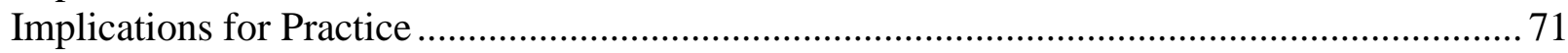

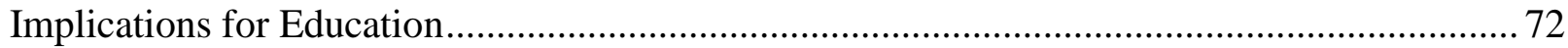

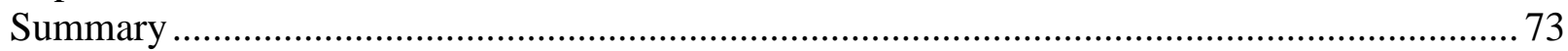

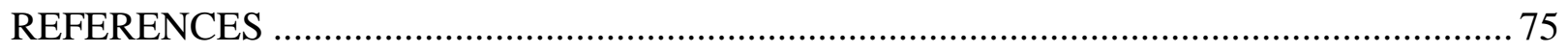

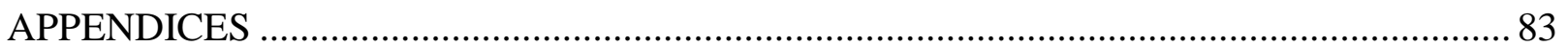


Living with migraine headache: A phenomenological study of women's experiences

\section{Chapter 1: Introduction}

Migraine headache is a significant health concern in this country and it is estimated that $18.2 \%$ of American women suffer from this chronic condition (Lipton, Stewart, Diamond, Diamond \& Reed, 2001). Lipton, et al. conducted a landmark study that revealed women are three times more likely to experience migraine headache than men. When women experience migraine headache, they feel intense physical pain (Lipton et al., 2001), that is often accompanied by nausea and vomiting, blurred vision, and feelings of complete disability (Kolotylo \& Broome, 2000a). The prevalence, symptoms, and effects of migraine headache have been extensively studied. To date, research has not been designed explore the meaning of living with migraine headache for women who experience this chronic illness.

The purpose of this chapter is to explain why migraine headache is an important health concern for nurses and to describe the importance of understanding the experiences of women with migraine headache. The gap in the current literature related to migraine headache is discussed, followed by a description of how qualitative work examining the experience of migraine headache will significantly contribute to the body of nursing knowledge. This chapter concludes with the presentation of the research question guiding this dissertation and a brief explanation of why the research method is appropriate for seeking answers to this question.

\section{Purpose}

The purpose of this study was to better understand the experience of women living with migraine headache through exploring the question, "What is the structure of meaning for women living with migraine headache?" A structure of meaning emerges when a description of the lived experience is dwelled with and reflected on, leading to the interpretation of core qualities that go 
together to create a structure that captures the meaning of the lived experience. Understanding the experience of women with migraine headache through the development of a structure of meaning will enable nurses to become better informed about various factors related to living with this often debilitating condition. Nurses who have enhanced appreciation of the phenomenon are better prepared to provide optimal care for women who suffer migraine headache, and ultimately help to improve the quality of their lives. Finally, this qualitative study may serve as a stimulus for future nursing research related to migraine headache.

\section{Definition of Migraine Headache}

Migraine headache is defined as a headache that lasts up to 72 hours when left untreated. This type of headache is usually limited to one side of the head (unilateral), produces moderate or severe pain, and may be aggravated by physical activity. Migraine headache is sometimes accompanied by nausea and/or vomiting, as well as sensitivity to light. Some women may experience an aura (e.g. loss of vision) before or during the migraine headache attack (Silberstein, Lipton, \& Dodick, 2008). Common terms used to describe a migraine headache include "migraine," "headache," and "sick headache". The terms "migraine" and "headache" are used throughout this dissertation to signify migraine headache.

\section{Background}

Lipton, et al. (2001) examined the prevalence and burden of migraine in the United States. Twenty-nine thousand seven hundred twenty-seven individuals from across the country responded to a mailed survey. With the purpose of determining the existence of migraine versus other types of headache, the associated symptoms of migraine, and the disability associated with migraine, the study determined that $16.6 \%$ of women living in the mid-Atlantic region experience migraine. Ninety-one percent of these women reported some form of functional 
impairment with migraine and $31 \%$ missed at least one day of work in the three months prior to the survey.

Migraine headache is a chronic illness with significant comorbities. The headaches and comorbities produce increased societal costs. A study revealed that nurses with migraine headache experienced a lower quality of life because of migraine headache (Durham et al., 1998). Migraine patients use the emergency room for care more than non-migraine patients and incur more medical care costs than those who do not experience migraine (Elston-Lafata et al., 2004). Researchers have identified other conditions that coexist with migraine headache. One such condition is depression, which frequently accompanies migraine and may be compounded when healthcare providers fail to acknowledge migraine headache (Kolotylo \& Broome, 2000b; Wikberg, Jansson, \& Lithner, 2000). Because migraine headache is a significant problem with possible comorbities for individuals who experience this chronic condition, and because migraine headache is related to increased societal costs, it is essential for nurses to better understand the overall experience of these patients. Phenomenological research may provide a better understanding of the migraine headache experience, in turn, leading to improved nursing care.

Migraine headache and the associated comorbities significantly impact women. The intent of this study was to explore the structure of meaning for women living with migraine headache. Therefore, the methodological approach chosen to guide this research was hermeneutic phenomenology, the study of persons. Hermeneutics is the description of a person's life interpretations and phenomenology is the description of a person's orientation to lived experiences. Hermeneutic phenomenology is rooted in philosophy and the human sciences. Van Manen (1997) states that phenomenology is an act of caring, that is, to understand another's 
world is to care for that person. Furthermore, phenomenology involves the understanding of what is unique to a person or persons (van Manen).

The aim of phenomenology is to better understand the essential nature of everyday experiences which is achieved as a person consciously reflects on life experience and interprets the associated feelings and thoughts to another person. From this reflection, embedded meaning surfaces for both the study participant and the researcher. As the researcher reflects on participant text, a deeper understanding of meaning emerges (van Manen, 1997). The philosophical underpinnings of hermeneutic phenomenology maintain that reflecting on a lived experience provides a rich understanding of meaning. The search for individual meaning in relation to living with migraine headache provides a natural fit with the interpretive phenomenology method described by van Manen (1997).

To further guide the acquisition of meaning from individuals with migraine, story theory, a middle range nursing theory, served as an additional framework for inquiry. The purpose of this theory is to "describe and explain story as the context for a nurse-person health promotion process" (Smith \& Liehr, 2008, p. 205). Story theory developed after Smith and Liehr realized that they each used story to guide their individual practice and research. Reed's (1995) developmental-contextual metaparadigm serves as the philosophical umbrella for the theory. Three interrelated concepts compose the basis of story theory. The first, intentional dialogue, is the "purposeful engagement with another to summon the story of a complicated health challenge" (Smith \& Liehr, 2008, p. 209). The second concept is connecting with self in relation, which is "the active process of recognizing self as related with others in a story-plot" (p. 210). The final concept, creating ease, "is an energizing release experienced as the story comes together in movement toward resolving" (p. 212). 
When applied to nursing research, story theory places the participant at the center of attention while the nurse researcher serves as an engaged guide. When conducting research involving women with migraine headache, the researcher asks the participant, "What is it like to live with migraine headache?" (Smith \& Liehr, 2008). As the story unfolds, the nurse researcher is charged with aiding the participant to clarify and connect the everyday thoughts and feelings of living with a health challenge. This connection leads to the realization of control over the situation and the researcher gains a thorough understanding of the participant's experiences. Once the participant has verbalized this experience, a sense of freedom and ease may result, leading to the formation of a new pattern of thought. Ultimately, the patient has, through story, attained a contextual realization (Smith \& Liehr).

The development of a rich description of the phenomena under investigation is a primary goal of phenomenology. This description is the result of the communication of the context from the participant perspective (van Manen, 1997). With these notions in mind, the fused connection between phenomenology and story theory offers a methodology for exploring the lived experiences of women with migraine headache.

\section{Significance}

Migraine headaches are a significant health issue for women (Lipton et al., 2001). These headaches produce intense localized pain, often accompanied by nausea, vomiting, and/or blurred vision (Lipton et al., 2001). Women with migraine may experience anxiety, depression, and/or feelings of isolation in addition to the pain of a migraine attack (Mongini et al., 2005). Furthermore, women report that migraine contributes to missed work and time with family (Lipton et al., 2001), possibly creating increased feelings of anxiety and/or depression. The increase in anxiety and/or depression is associated with increased occurrence of migraine 
headache. The literature indicates that migraine headaches are best treated through the identification of migraine triggers, decreasing stress, and with the use of both prophylactic and abortive medications (Wright, 2008).

The body of nursing and medical knowledge revealed that in spite of migraine treatments, women with this type of headache may live in physical and emotional pain (Lipton et al., 2001). Women living with migraine headache could possibly have low expectations in regard to prevention and treatment of migraine headache (Peters, Abu-Saad, Vydelingum, Dowson, \& Murphy, 2004). The extant literature suggests that women with migraine headache often experience physical and emotional pain and may have low expectations in regard to their prevention and treatment. As a result, women with migraine headache may choose to self-treat or have limited confidence in the healthcare system to help them (Ruiz de Velasco, Gonzalez, Etxeberria, \& Garcia-Monco, 2003; Belam et al., 2005). The authors of each study signified that more qualitative research is needed to better understand the many aspects of living with this debilitating condition.

The literature review revealed a significant gap in our understanding of the meaning of the illness experience for women living with migraine headache. The research question for this dissertation was developed because this gap in the literature exists. The question was expected to capture what other studies have missed. For example, the study revealed many feelings women with migraine headache experience, but have not been reported in the literature. The research presented the opportunity to seize themes never before identified in relation to the day-to-day life of women with migraine. Finally, this study may serve as a foundation for future research related to migraine headache. 
LoBiondo-Wood and Haber (1998) challenge nurses to "offer creative approaches to old and new health problems" (p. 6). Exploring the lived experience of women with migraine headache reexamined the long-standing health challenge of migraine headache with a research question designed to gather new information related to what it is like for women to live migraine headache. Gathering the stories of women with migraine headache presented the opportunity to influence nursing practice through the provision of new insight related to the self-management of migraine headache, migraine headache therapies and prevention strategies, interactions with healthcare providers, and the social impact of migraine headache. This study informs nursing care at the bedside (LoBiondo-Wood \& Haber, 1998).

Phenomenological research identifying the experiences of women with migraine headache is limited at best. Research based on the question, "What is the structure of meaning for women living with migraine headache?" was not located in the literature review. This study is expected to generate new knowledge, addressing a significant gap in the literature. With this knowledge, nursing care could become better informed so that women with migraine headache will achieve optimal outcomes related to the migraine headache experience.

\section{My Story}

Because this study was phenomenological in nature, I believed that it was important for me to critically review my thoughts and feelings regarding migraine headache. This reflection created an avenue for "examining personal commitments and prejudices prior to beginning data collection" (Cohen, 2000a, p. 38). I have never had a migraine headache and rarely experience any type of headache. My interest in migraines began while I was working as an emergency department nurse. In this setting, I would often encounter women with a severe headache. Some 
of these women shared with me that they often felt as if they would never live a migraine-free life. Some held hope that relief would one day be found.

As I began doctoral studies, my research interest returned to these women. I developed a migraine clinic at a local clinic for uninsured patients. I hold this migraine clinic once each month. This clinic has allowed me to experience the happiness of reducing a woman's migraine headache occurrence from ten headaches per month to two headaches per month. Conversely, I have experienced the frustration of working with a woman for over one year with no significant reduction in headache occurrence. The fact that I can provide the same level of care and have two opposite patient outcomes leads me to wonder why some women respond to treatment plans and others do not. This thinking, combined with a significant gap in the literature related to the meaning of migraine for women and my personal inexperience with headache, reaffirmed my commitment to the question, "What is the structure of meaning for women living with migraine headache?"

I recognize that I have become close to the patients I work with at this clinic. Therefore, to maintain my credibility as a researcher and to protect the women I care for in practice, I chose study participants from a different setting. Although I do not know the pain of migraine headache, I believe that the pain these women experience is real and that some women with migraine seem to be on a lonely journey in relation to their headaches. I believe that some women find healthcare providers, especially male providers, to be insensitive when treating migraine. I consider myself to be an understanding man, capable of working in a clinic with women, and perhaps more importantly, capturing the meaning of migraine headache for women. 


\section{Conclusion}

Migraine headache is a condition that affects many women. Nurses in any setting are poised to provide exceptional care for women with migraines. However, nurses have not researched migraine headache with the goal of understanding the structure of meaning for women living with migraine headache. The qualitative research was intended to serve as a starting point for providing a voice for women with migraine headache. Guided by van Manen's (1997) phenomenological method and story theory, this researcher believed that this research might provide first-hand insight into the experience of migraine headache. Although nursing and other disciplines can benefit from this research, it was the woman with migraine headache who was driving my desire to do this work, and it is she who may benefit most from this work. 


\section{Chapter 2: Literature Review}

Migraine headache has been described by scientists, physicians, and other writers for thousands of years. Early descriptions appeared as poems or through other written expressions. The earliest documentation of migraine headache noted in the literature was nine thousand years ago (Magiorkinis, Diamantis, Mitsikostas, \& Androutsos, 2009). Authors believe that early writings and descriptions resulted, in part, from personal experiences with headache (Silberstein, Lipton, \& Dodick, 2008). The literature presented throughout history varies little in the description of migraine headache symptoms. The ways the migraine experience have been explored include the study of anatomy and physiology of migraine, the study of migraine treatments including medications, the study of the impact of migraine on daily life, and the study of migraine prevention strategies. Migraine has been studied in a variety of ways, including quantitative descriptive, historical, and qualitative methodologies.

The purpose of this chapter is to describe the headache research through presentation of the literature. Beginning with an historical overview, this literature review presents what is known about migraine headache among women and the methods used to generate this knowledge. This chapter concludes with a discussion of the gaps in the literature and justification for research exploring the meaning of the experience of migraine headache for women.

\section{An Overview of the History of Migraine Headache}

Multiple databases were examined for literature related to the historical perspective of migraine headache. These databases included CINAHL, PUBMED, Academic Search Premiere and ERIC. Key words and phrases to locate relevant information included: migraine, migraine history, migraine historical perspective and history of migraine. The title and/or abstracts of hundreds of articles were examined for relevance. The references of articles were also retrieved 
and examined for relevance. Numerous texts are available related to the history of migraine headache. The section presents a synthesis of the most notable references.

Ancient writings described migraine headache, associated symptoms, and folk remedies. Alvarez (1963) proclaimed that he was "satisfied that men have suffered migraine ever since the dawn of written history." He presented evidence that supports this statement, including a poem from ancient Mesopotamia: "The head throbs, / When pain smites the eyes / And vision is dimmed." People during this period believed that migraine headache was caused by an evil spirit known as Ti'u. Removal of the evil spirits through rituals was the suggested cure for migraine at that time. It was not until the Middle Ages that opium was found to effectively treat migraine headache (Magiorkinis et al., 2009).

Willis's (1621-1675) description of Lady Conway and her recurrent headaches is probably the first description of chronic migraine headache in history (Silberstein et al., 2008). Of particular importance from Willis's work came an initial theory of vascular involvement in migraine headache. He believed that the symptoms of migraine indicated spasms that began at peripheral nerve endings and ascended throughout the body (Magiorkinis et al., 2009). Willis, who also introduced the term "neurology," recommended in his writings the use of coffee as a treatment for migraine, a very wise choice by today's standards (Silberstein et al., 2008). However, later work by Living described the disease of migraine and proclaimed that nerve involvement was present in megrim as well as vasodilatation. This debate of vascular versus neurogenic causes of migraine continues even today (Silberstein et al., 2008).

At the beginning of the twentieth century, migraine headache writings continued to focus on the pathophysiology, triggers, and treatment of migraine headache. These writings included the idea that migraine headache was indeed an important illness to treat and research. The 
migraine headache work by Birtch (1910) portrayed an emergence of migraine literature that occurred in the early 1900s and indicated the experimental processes frequently utilized during this period in migraine history. Moffitt (1911) reported that his observations indicated that migraine is a disease of the brain, is inherited from family members and is not absent when stress is reduced. Later, in the 1930s and 1940s, vasodilatation of cephalic arteries was reported to be the primary cause of migraine headache, a theory that has stood the test of time. Drugs such as ergotamine and caffeine were employed to induce vasoconstriction and relieve migraine pain (Silberstein et al., 2008).

Since the confirmation of vasodilation as a potential cause for migraine, ergotamine and other abortive therapies were developed in the 1930s and continue to be used today. The idea of migraine prophylaxis was introduced in the mid-twentieth century, creating a two prong approach to drug therapy for those with migraine headache (Riley, 1932). Drugs such as propranolol and amitriptyline are still used today as prophylactic agents, often significantly reducing the occurrence of migraine headache (Ziegler et al., 1987). In addition to drug therapy, positron emission tomography (PET) and magnetic resonance imaging (MRI) are used to detect the functional changes that occur in the brain when migraine headache is present (Silberstein et al., 2008). Neuromodulator drugs including divalproex and topiramate have been incorporated into therapy as effective prophylactic drugs, even though their mechanism of action is unknown at this time (Solomon, 2007). These twentieth century and twenty-first century advances offer new understanding regarding the causes of migraine headache and have significantly changed the treatment of migraine headache.

It is evident from this brief historical review that migraine headache has been a health issue for thousands of years. Through observation and research, an understanding of the 
pathophysiology, triggers, and treatment of migraine headache has emerged. This understanding has contributed to advances that provide relief for many people who suffer with migraine headache. Although diagnosis and treatment of migraine headache has been discussed from a variety of perspectives, historically there has been little to no research that focuses on understanding the nature of what it is like for people to live with migraine headache.

\section{Women and Migraine Headache}

The literature indicates that women experience migraine headache at a significantly higher rate than men. This statement is strengthened through the dissemination of a landmark study that included more than twenty-four thousand participants and revealed that women are three times more likely to experience migraine headache than men (Lipton et al., 2001). To further examine literature specific to women with migraine headache, a literature search was conducted using the library engines PubMed, CINAHL, and Academic search Complete. Thousands of results appeared when the keywords "migraine" and "women" were entered into the search engines. Drug trials were eliminated from the search to narrow the results. The studies which best inform this study are presented below.

Migraine and hormones. A primary difference between men and women is the existence of specific reproductive hormones in women. Vujevich (2007) reported that hormones make migraines different for women than for men. Through the presentation of case studies, this author described a 17-year-old non-pregnant girl with menstrual related migraines, a 26-year-old pregnant woman with migraines and a 51-year-old premenopausal woman with migraines. The proposed best treatment for each was individualized based on the respective physiological actions, or lack of actions of the reproductive hormones in each case. Both the prophylactic and 
abortive migraine medications for each of these patients would be different because of individual hormonal roles related to their current stage in life (Vujevich, 2007).

To better understand the role of reproductive hormones, Brandes (2006) conducted a systematic review of MEDLINE and EMBASE articles related to estrogen and migraine headache published during the years 1966-2005. Brandes concluded that migraine headaches related to menstruation are more difficult to treat, and that this may be true, in part, because estrogen withdrawal stimulates migraine. The author suggested the addition of small quantities of estrogen to offset the occurrence of migraine. He stated that the evidence clearly supports the need for best practice guidelines related to this therapy. This study did not examine the effects of estrogen during pregnancy or during the perimenopausal phase; however, this systematic review confirmed that estrogen is strongly linked to migraine headache (Brandes, 2006). This finding suggests a reasonable explanation for the significantly increased incidence of migraine in women over men reported in the literature.

In the article Hormonal Status (2007) the role of estrogen was presented through the use of descriptive tables. It appears that most women with menstrual migraine headache develop the headache during the period of two days before and three days after the onset of menstruation. The estrogen-migraine link is further supported by the fact that migraine headache decreases during the second and third trimesters of pregnancy when estrogen levels are at their highest. The evidence indicates that migraine headache returns after delivery. The post-menopausal phase brings about the stabilization of sex hormones. However, the erratic nature of these hormones during menopause is linked to a worsening of migraines during the period prior to stabilization (“Hormonal status," 2007). Understanding these key concepts of estrogen's role in migraines and 
its presence at different points in life is a foundational building block when composing a study related to women with migraine.

With the exception of dysmenorrhea, menstrual migraine is the most frequently reported menses related symptom (Mannix, 2008). However, menstrual related migraine is, for the most part, treated in the same fashion as non-menstrual migraines. The prophylactic drugs low-dose estrogen, beta-blockers, propanolol and amitriptyline are all reported as frequently prescribed drugs intended to decrease the occurrence of migraine. To abort migraine, ergotamine, the triptans, and NSAIDS are employed. Frequently used non-pharmacological treatments include ice to the head, avoidance of triggers, and stress reduction (Weitzel, Strickland, Smith, \& Goode, 2001). The treatments listed here are not an exhaustive list; instead they are listed to paint a picture revealing that, based on the literature, migraine therapy appears to be the same regardless of the type of migraine. An important realization from this review is the fact that all but one (hormone replacement) of these treatments does not address estrogen specifically.

Personality and migraine. In addition to understanding estrogen's role in migraine, researchers and practitioners examine the literature for the personality characteristics linked to women with migraine. A study examined the personality of seventy women with migraine headache through the use of the Myers-Briggs Trait Indicator (Gallagher, Mueller, Steer, \& Ciervo, 1998). The authors found that the women in this study may be prone to overreacting to stressful situations. Additionally, these participants were found to have unrealistically high expectations for others, and at the same time, tended to avoid controversy. The authors suggested that self-imposed deadlines by this group may lead to stress related illness, such as chronic migraine headache (Gallagher et al., 1998). 
The Temperament and Character Inventory (TCI), another well validated tool, was used to assess a sample of women with migraine headache (Mongini et al., 2005). Forty-nine women with migraine were compared to a control group of 47 women without migraine or psychiatric disorders, but of similar age and education. The women with migraine scored significantly higher in the areas of harm avoidance and persistence, indicating they may be fearful, passive, and insecure as well as prone to reacting to stress with a higher level of anxiety (Mongini et al., 2005).

The literature revealed that women may experience migraine headache because of hormonal fluctuations (Vujevich, 2007; Brandes, 2006). There also appeared to be a link between specific personality traits and women with migraine. However, when the migraine literature was examined closely, few studies specifically related to women and their experiences of living with migraine headache were located. Therefore, a qualitative study that explores what it is like for women to live with migraine headache was warranted.

\section{Quantitative Research Studies}

The quantitative literature was examined to identify studies that discuss the meaning of living with migraine headache or describe what it is like for women to live with migraine headache. The search terms "migraine headache," "migraine headache communication," and "migraine headache tool" were entered in to the library search engines CINAHL, PubMed, and Academic Search Complete. Once drug studies were eliminated, experiences of living with migraine headache appeared in articles discussing the development and implementation of assessment tools. Each tool appeared to be used primarily in practice. A discussion of the results is presented below. 
The tools located in the review are well developed, hold sound psychometric properties, and serve as a screening method. The instruments reported in the literature relative to migraine headache pain were the Diagnostic Diary (Nappi et al., 2006), the Migraine Assessment Tool (Marcus, Kapelewski, Jacob, Rudy, \& Furman, 2004), and the Migraine-Specific Quality of Life Questionnaire Version 2.1 (Martin et al., 2000). Although discussed throughout the literature, only one study which validated the use of the 11 Point Numeric Rating Scale with migraine patients was located (Kwong \& Pathak, 2007). The predominant instrument in use was the Migraine Disability Assessment Questionnaire (Stewart, Lipton, Dowson, \& Sawyer, 2001).

In general, the Diagnostic Diary provides the patient a means of tracking specific headache triggers, associated symptoms, and a detailed description of pain. These diaries have been further developed for specific populations, including children and women. For those designed for women only, a primary advantage is the ability to display the key indicators of the menstrual cycle in addition to the triggers and associated symptoms. Arrays of headache diaries are available for use and are easily located on the World Wide Web (Nappi et al., 2006). However, validation reports related to these diaries were not located.

The Migraine Assessment Tool (MAT) is an 8-item screening instrument for the diagnosis of migraine designed to be administered by nurses. It is not necessary for nurses to have specialized headache training to administer the tool. The tool is administered by reading each item verbatim and recording the responses. The tool captures recent headache history including abnormality diagnosis or trauma, medications used for headache, associated symptoms, and the quality and duration of the headache. The tool is reported to have acceptable reliability and validity (Marcus et al., 2004). This instrument is relatively new and has not been studied extensively. However, one occupational health nurse review suggested that nurses using 
this tool may expedite the diagnosis and treatment of migraine, providing additional support for the potential of this tool in nursing practice (Berry, 2007).

The developers of the Migraine-Specific Quality of Life Questionnaire (MSQ Version 2.1) identified 14 items to capture the role-restrictive, role-preventive, and emotional function dimensions of living with migraine. Reliability and validity measures exceed standards on each dimension (Martin et al., 2000). The tool has been used in numerous studies including a recent drug trial concerned with quality of life improvement for migraine patients (Smith et al., 2007). The instrument was recently validated for use in migraine patients using prophylactic therapies (Cole, Lin, \& Rupnow, 2007). The MSQ is easy to administer and does not appear to place excess burden on the participant.

Kwong and Pathak (2007) provided the only study located in this review to validate the 11-Point Numeric Rating Scale. They determined that the $0-10(0=$ no pain, $10=$ worst pain possible) scale is $55 \%$ more sensitive than a 4 -point scale (none, mild, moderate, severe) in determining important clinical differences with migraine patients. The researchers determined that although the 4-point scale is often utilized throughout the migraine literature, the eleven point scale is valid for use in migraine research as in other pain states. The literature indicates that the 11-point scale has been used in research and practice for some time. Currently, the 11point scale is included in a predominant instrument, the Migraine Disability Assessment Questionnaire (MIDAS). However, the 11-point scale is not a part of the MIDAS score; instead the numerical rating is used as a clinical guide (Stewart et al., 2001).

Designed as a migraine disability communication tool, the MIDAS is a heavily utilized seven-item questionnaire that incorporates a scoring range of $0-21+$. Developed specifically for those with migraine, headache sufferers are asked to recall the previous three months and insert 
the number of days they miss work or school (Question 1), missed housework days (Question 3), and missed days of leisure, family, or social events (Question 5). Additionally, the headache sufferers are asked to insert the number of days they experience a $50 \%$ reduction in productivity at work or school (Question 2) and housework (Question 4). The five questions are then totaled to provide a score for grading. Grade I (score 0-5) is defined as minimal or infrequent disability. Grade II (score 6-10) is defined as mild and infrequent disability. Grade III (score 11-20) translates to moderate disability, with Grade IV (21+) indicating severe disability. These four grades predict the patient's treatment needs, with Grade I indicating low need and Grades II-IV indicating high medical need (Stewart et al., 2001). Subscales are not utilized within MIDAS.

The MIDAS Questionnaire has been extensively tested for reliability and validity (Stewart, Lipton, Kolodner, Liberman, \& Sawyer, 1999; Stewart et al., 2000; Stewart et al., 2001) and has been used throughout the world as a means for determining migraine disability in practice and research. A review of the literature in PubMed, CINAHL, and Academic Search Premiere revealed that the instrument has been translated and validated in Brazil, Italy, Japan, Taiwan, and Turkey, as well as in the United States. Also in the United States, a pediatric version of the tool was created and tested for validity. The tool is easily accessible to patients and providers at www.midas-migraine.net. From the literature, it appeared that physicians have utilized MIDAS most in practice and research. Nursing reports of MIDAS utilization within research or practice were not located.

The literature located in this review indicated that migraine headache has become a significant area of research during the last twenty years. Quantitative studies have focused on migraine headache triggers, associated symptoms, and pain. The studies selected for review addressed the meaning of living with migraine headache based on descriptive categories. The 
review revealed that the quantitative literature is rich with practice tools that address the perspectives of pain, disability, and triggers associated with migraine headache. However, a significant gap regarding the meaning of living with migraine exists. This gap can best be addressed with a phenomenological study designed to capture the meaning of living with migraine headache from the perspective of a woman.

\section{Qualitative Research Studies}

A review of the qualitative literature was conducted to determine whether any qualitative studies have addressed the meaning of living with migraine and to identify the study methods employed regarding women with migraine headache. The search term "migraine qualitative research" was entered into PubMed, CINAHL, and Academic Search Complete. PubMed produced 29 results, CINAHL produced 23 results, and Academic Search Complete produced 17 results. After the abstracts were reviewed for relevance, seven pertinent articles were selected for this review based on the title that addressed some aspect of living with migraine headache. These studies used a variety of methodologies, including grounded theory, focus groups, content analysis, and concept development. The findings of the studies include the perception of migraine headache pain, difficulty communicating headache pain, desire for relief from the pain, and the impact of migraine headache pain in regard to daily life.

A team of researchers from the United Kingdom and Lebanon conducted migraine headache research and presented two articles (Peters, Abu-Saad, Vydelingum, Dowson, \& Murphy, 2004, 2005). Using a convenience sample of 13 participants composed of nine women and four men ages 24-60, the researchers entered the first study with the intention of better understanding patient's perceptions of headache as well as their experiences of headache (Peters et al., 2005). A semi-structured interviewing technique, followed by research team discussions, 
allowed the researchers to arrive at three themes from the interviews: headaches, headache impact and headache as a health issue. Headache was identified as a theme and included the various definitions of headache, severity of migraines and the participant's perception of pain. Headache impact involved the participant's ability to perform everyday tasks. Headache as a health issue was related to the meaning of headache and health to the participant. Embedded within these themes was the notion that the participants do not think that a headache is serious enough to seek medical attention or to "bother" the healthcare provider with the issue. The authors stressed the importance of more qualitative research to better inform practice (Peters et al., 2005).

The same team of researcher's explored patients' perceptions related to the management of migraine headache (Peters, Abu-Saad, Vydelingum, Dowson, \& Murphy, 2004). This study used a grounded theory methodology for interviewing thirteen participants. The researchers found that the participants had low expectations regarding care from the general practitioners they saw for their migraines. Furthermore, they believed that little attention was given to uncovering the cause of the headaches when they sought care. The authors noted the "central role the participants assigned to their involvement (self-management) in their headache care..." as a major finding (Peters et al., 2004, p. 301). The participants saw themselves as the key decisionmakers and as a resource to themselves in the management of migraines. The authors indicated that qualitative studies related to the wide-spread issue of migraine headache are warranted (Peters et al., 2004).

Belam, et al. (2005) took the approach that the participant is an equal partner in the research process, adding validity to the findings discussed below. This approach was achieved by combining a grounded theory method with a participatory research model. Eight participants, 
ages 30-61, including two men, recruited with purposive sampling contributed to the authors' aims of developing a research partnership while raising awareness of suffering from migraine from the participant's perspective. "Handling the beast" was the metaphor that emerged as an over-arching theme in the study (Belam et al., 2005, p. 89). The "Beast" was handled through making sense of the problem, putting up with it and doing something about it. Not all participants could make sense of the problem, but all stated that talking with the researcher helped. The majority of the participants were pessimistic regarding relief from the headaches and many of them pursued self-help measures because they found little relief with traditional healthcare services. The authors stated that they accept the lack of rigor that became apparent when they decided to train and utilize study participants to interview other study participants. However, they stated that this method brought different experiences into the study that would have otherwise been lost. This team of researchers indicated that future qualitative work regarding migraine headache is warranted (Belam et al., 2005).

Two studies relate to quality of life in migraine patients. Using a focus group approach in Spain, Ruiz de Velasco and colleagues found that migraine headache significantly decreases the quality of life for patients, especially in the areas of work, personal relationships, and recreation. The study paints a picture of social isolation for the participants and the authors report that this study supports the notion that those with migraine may hold a lack of confidence in healthcare providers. Furthermore, the participants who self-treated migraines experienced equal frequency and severity of migraines as those treated by healthcare providers (Ruiz de Velasco, Gonzalez, Etxeberria, \& Garcia-Monco, 2003).

Using a purposive sample of 22 women and grounded theory analytical methods, Meyer (2002) discussed how women may constantly be on guard for a potential migraine. For instance, 
when confronted with a migraine trigger, women with migraine may ask themselves, "could this bring on a headache?" (Meyer, 2002, p.1226). These women may constantly scan the environment for migraine triggers. Moreover, these participants were often in a situation where they had to decide if the risk of the trigger was worth the need for treatment if a migraine headache occurred. Most of the women were found to always be ready for a migraine by having their medications on hand. A limitation of this study was the fact that all of the participants had health insurance, indicating that they may be of the socioeconomic level to always have that medication on hand (Meyer, 2002). Regardless of this limitation, this study brought forth the significant challenges women face on a daily basis in regard to migraine headache.

Moloney, Strickland, DeRossett, Melby, \& Dietrich (2006) took a more specific approach to assessing the experiences of middle-age women with migraine through interviewing, focus groups, and questionnaires. The aim of this study was to understand the perceptions of women with migraine in the context of perimenopause. During the qualitative phase, the researchers encouraged reflection related to the objective and found that the participants often used story to relate their perceptions. Three patterns emerged from the stories. Pattern one was changing headache patterns and the context of the headache at each stage. The second pattern was the description of migraine triggers and control over the headaches. The last pattern was the description of migraine's influence on relationships and daily life. A major theme from these patterns was that the women in this study constantly strive for control over the headaches through managing medication stores, and self-monitoring triggers. This report noted that a stigma is attached to experiencing migraine. The women in this study felt as if others judge them for missing work and needing medication. Much like the previous authors, the authors of this 
study held that considerable information related to the migraine experience is missing in the current literature (Moloney et al., 2006).

Through content analysis of narrative data within a survey administered to 127 participants with migraine headache, Vick and Sexton-Radek (2005) discovered that those with migraine headache may not benefit as much from art therapy as others with chronic pain. The researchers found that odors of the paints and chemicals, bright colors and the lighting of the studio were all reported by participants as significant migraine triggers, decreasing the therapeutic value of art and painting. Another finding in the surveys was the fact that the respondents reported feelings of being highly creative, but this creativity seemed to come only during a migraine headache, a time when they were physically unable to get the creativity to the canvas because of the suffering associated with the headache (Vick \& Sexton-Radek, 2005). This finding suggests a possible neurological component of migraine therapy that was not discussed in other studies included in this review. Furthermore, the findings in this study suggest that migraine headache relief measures may serve as migraine headache triggers, warranting further research.

The literature presented in this section examined migraine headache through various qualitative research methods. Lack of attention from healthcare providers, social stigma with migraine, and statements of dependence on self are themes located in this literature review. One study indicated that therapies intended to aid in preventing migraine headache may actually serve as a headache trigger (Vick \& Sexton-Radek, 2005). The meaning of living with migraine headache is missing from the qualitative literature. The themes from the studies and the identified gap in the literature provide substantive support for phenomenological research asking the question, "What is the structure of meaning for women living with migraine headache?" 


\section{Synthesis}

The literature related to migraine headache is abundant. The experiences of migraine headache have been documented through various sources for thousands of years (Magiorkinis et al., 2009). Numerous sources support the notion that women experience migraine headache more often than men, primarily due to hormonal influences (Vujevich, 2007; Brandes, 2006).The quantitative literature has focused on the incidence of migraine and its comorbities, discussion of migraine treatments, and the development of tools to communicate the level of migraine associated disability (Lipton et al., 2001).The qualitative literature indicates that women with migraine headache may experience relief when sharing their stories (Belam et al., 2005), might believe that their headaches are not important (Peters et al., 2005), and may feel that others will judge them for missing work and taking medications (Moloney et. al., 2006).

The stories of women with migraine were not adequately presented in the literature. There was a gap in the literature regarding what it is like for a woman to live with migraine headache. Findings from the literature review supported the need for qualitative work that addresses the question, "What is the structure of meaning for women living with migraine headache?" This study was designed to address this gap in the literature by exploring the meaning of migraine headache from a woman's perspective. 


\section{Chapter 3: Methodology}

The research question addressed in this study was, "What is the structure of meaning for women living with migraine headache?" A review of the literature related to migraine headache indicated that a gap existed in regard to understanding what it is like for women to live with migraine headache. Qualitative research methods are often utilized when little information exists concerning specific phenomena such as migraine headache in women. Because phenomenology studies how people make meaning of experiences, phenomenology is an appropriate qualitative research method for this study (Cohen, 2000b). This chapter presents the philosophical underpinnings which serve as a guide for this research. Discussion of the underpinnings includes hermeneutic phenomenology and a description of story theory, a middle range nursing theory. The remainder of the chapter centers on the procedural steps of the methodology. These steps include a description of the recruitment of participants, a discussion of data collection and analysis, the maintenance of rigor, and the protection of human subjects throughout the study.

\section{Philosophical Underpinnings}

The literature revealed a lack of information about the experience of migraine headache for those who suffer with this health concern. To better understand the experience of living with migraine headache, hermeneutic phenomenology guided this research. Hermeneutic phenomenology was chosen over other qualitative methods because this method of inquiry captures the lived experience (Van Manen, 1990). Lived experience is defined as "the breathing of meaning" (Van Manen, 1997, p. 36). The researcher's role is to facilitate the realization of the meaning of an experience and give that meaning a voice through the use of text. Van Manen, whose work guided this dissertation, maintains that phenomenology is "the systematic attempt to uncover and describe the structures, the internal meaning structures, of lived experience," (Van 
Manen, 1997, p. 10). At the practical level, hermeneutic phenomenology allows the nurse to understand the perceptions and needs of another (Cohen, 2000b). Once nurses understand these perceptions and needs, nursing care and research can create avenues for optimal care.

\section{Phenomenology as a Philosophy and a Research Method}

Phenomenology is considered both a method and philosophy (Dowling, 2007). Although the term phenomenology was used in earlier literature, phenomenology did not enjoy prominence until Husserl presented it as a radical philosophy intended to connect with the experience of living (Moran, 2000). Although he is considered the father of phenomenology, Husserl's ideas were influenced by Brentano, who served as Husserl's teacher for two years. Brentano believed that descriptive phenomenology would move his discipline of psychology to become a scientific based discipline. Husserl adopted Brentano's idea that every mental act is connected to an object, an idea Brentano labeled as intentionality (Dowling, 2007; Moran, 2000).

Husserl indicated that experience is the foundation of knowledge, and this experience of the lifeworld should be described before it is reflected on (Dowling, 2007). Another phenomenological concept Husserl developed was eidetic reduction or bracketing, the reduction of fact to essence. "Essence is what makes a thing what it is (and without which it would not be what it is)" (Dowling, 2007, p. 133). To bring forth the essence of an experience, one must access the natural (original) thought because the natural thought is not present in one's everyday life. "We take what is commonplace so much for granted that we often fail to notice it, and, therefore, phenomenological study is required" (Cohen, 2000b, p. 8). Phenomenology describes that which appears to the conscious (Moran, 2000).

Heidegger, who studied under Husserl, rejected Husserl's idea that phenomenology, should be descriptive. Instead, Heidegger believed that understanding the phenomena is the 
importance of phenomenology (Dowling, 2007). From both Husserl and Heidegger, hermeneutic phenomenology emerged. Hermeneutic phenomenology, "in practical terms ... will study how people interpret their lives and make meaning of what they experience" (Cohen et al., 2000b, p. 5). Van Manen $(1990,1997)$ utilized a combination approach to phenomenology that included both the description of an experience and the interpretation of that experience. Van Manen maintained that there is no such thing as un-interpreted phenomena. He believed that the lived experience is best understood when interpreted and written (description).

\section{Van Manen's Approach}

Van Manen did not prescribe a specific method of phenomenological inquiry. Instead, he believed that the broad body of phenomenological knowledge should be used to guide phenomenological work. This approach honors the phenomenological tradition without the required adherence to a particular linear thought or set of thoughts. He believed that instead of using predetermined techniques and procedures to guide a research project, the researcher should embrace the idea that he or she is a scholar who observes the details of everyday life (Van Manen, 1997). However, van Manen also believed that there is a foundational base of tradition built by "thinkers and authors" that serves to guide researchers, particularly beginning researchers (Van Manen, 1997, p. 30). This tradition has revealed six methodological activities which serve as a guide for research and follows a hermeneutic path:

- turning to a phenomenon which seriously interests us and commits us to the world;

- investigating experience as we live it rather than as we conceptualize it;

- reflecting on essential themes which characterize the phenomenon;

- describing the phenomenon through the art of writing and rewriting;

- maintaining a strong and oriented nursing relation to the phenomenon; 
- balancing the research context by considering parts and whole (Van Manen, 1997, p. 30$31)$.

These six activities warrant further explanation. Van Manen (1997) first stated that research should begin with a phenomenon that interests us. To do this, one must orient to the concrete and essence of the phenomenon. In other words, one must have an interest in the phenomenon and that phenomenon can be anything of interest. This interest results in the formation of a question. For example, interest in this phenomenon developed through the investigator's clinical experiences of caring for women with migraine headache and wondering, "What is it like to live with migraine headache?" The question, "What is the structure of meaning for women living with migraine headache?" is the result of that interest. Secondly, to capture the essence of the experience (phenomenon), the researcher must reawaken the experience itself. Once the experience is reawakened, it is interpreted as it is lived rather than how it is conceptualized (Van Manen, 1997).

The third activity, reflecting on essential themes, holds that the appearance of a lived experience is not the essence of that experience. Instead, lived experience is capturing the obscure that evades natural (everyday) attitude, and bringing the obscure to the forefront. Van Manen believed that the core of phenomenology is giving voice to a lived experience. He also believed that thought and voice cannot be separated. The fourth activity centers on the art of writing and rewriting, allowing the voice of the experience to develop and be heard (Van Manen, 1997).

The fifth activity describes remaining attentive to the original question. Van Manen, while describing the sixth activity, recommends the examination of the parts of writing as well as the whole of the writings for significance. He warns that as writing begins, it is easy to enter a 
writing trap when the answers are found within what is already written. Finally, van Manen believed these activities are not procedural steps to be followed one after another. Instead, the work may consist of using the themes at intervals, or using only various aspects of the themes (Van Manen, 1997).

\section{Story Theory}

As stated in the introductory chapter, the middle range nursing theory of story theory was also a guide for this research because "stories are the substance of qualitative research" (Smith \& Liehr, 2008, p. 219). Therefore, the investigator, as a nurse researcher, gathered the stories of women with migraine headache to reveal the ontological understanding of what it is like to live with migraine headache. This understanding fuses the philosophy of hermeneutic phenomenology with the idea that the sharing of the story creates an avenue of understanding for both the researcher and the participant (Smith \& Liehr, 2008). This understanding leads to a new realization of meaning for the participant and the researcher who will disseminate this understanding through writing, just as van Manen suggests above (1997). Following van Manen's beliefs, and story theory, the aim of this research was to capture women's experiences of living with migraine headache. Through the reflections on the lived experience of migraine headache, significance and deep meaning emerged.

\section{Recruitment}

Institutional Review Board approval was obtained from both West Virginia University (Appendix A) and Radford University (Appendix B). Recruitment of participants was achieved by sending an e-mail with a study advertisement (Appendix C) to everyone who holds a Radford University account and by placing advertisement flyers in various buildings located on the Radford University campus. This advertisement included a description of the study and contact 
information for anyone wishing to participate in the research. By the end of the same day that the advertisements were distributed, 59 people had responded saying they would like to volunteer for the study. Within one week of the advertisement distribution, a total of 93 people responded stating their interest in study participation.

Women who were younger than 18-years-old, reported headaches other than migraine, or did not speak English were excluded from the study. Two men were excluded from the study because the research was designed to learn what it is like for women to live with migraine headache. Because of the large number of people who indicated a willingness to participate in this study, the researcher decided to initially contact those volunteers who supplied a phone number. The researcher began by contacting the first 12 volunteers who provided phone numbers, assured that each met the requirements for participation, and provided them with more information regarding the study. Other volunteers were informed that they would be contacted at a later date, if necessary, for additional data collection.

Each of the initial 12 volunteers was contacted via phone and scheduled a tentative interview date. There was the understanding that the participant could cancel or reschedule the interview at any time. Two volunteers declined this study. The concept of data saturation was explained to each volunteer, who understood that the study may be suspended by the researcher if saturation occurred. All of the volunteers who were not selected for this study were e-mailed a letter of appreciation, and asked if their contact information could be kept on file for future studies. One hundred percent of the volunteers agreed to their information being retained, and to the researcher contacting them at a later date if needed for this study, or for future studies. 


\section{Ethical Considerations}

After approval by the dissertation committee, the investigator submitted the proposed study to the Institutional Review Board (IRB) for Protection of Human Subjects of West Virginia University and Radford University. After the IRB approvals were obtained, the recruitment process described above was initiated. Those volunteering to participate were given a letter (Appendix D) describing the study, informing them of their right to refuse to participate in all or any part of the study, methods to protect privacy, such as separating identifying information from data, and a statement that any publications or public presentations of findings of the study will not include their name or any identifying information. All participants were required to sign a consent form prior to the interview and after the complete study had been explained in detail. Each participant understood that she could refuse to provide demographic data and/or stop the interview at any point. The investigator had emergency telephone numbers of health providers and mental health providers on hand (Appendix E) in case the participant experienced distress during the interview process. The researcher informed each participant that she could review the transcription at any point she desired. Participant confidentiality was maintained throughout the study. The transcriptionist did not have access to the participant information and the recordings were erased after data analysis was complete. The demographic data and transcribed interviews were secured in a locked file cabinet located at Radford University in Waldron Hall, room 329 (a locked office) and will remain there for 7 years after analysis and then be destroyed. 


\section{Data Collection}

Bracketing was addressed in Chapter 1 with the inclusion of "my story" and was addressed again through journaling prior to the beginning of data collection. It is the researcher's responsibility, according to van Manen, to come to terms with all that he or she thinks and knows about women with migraine headache through bracketing. To explicate these thoughts and ideas allowed the investigator to set them aside.

Each participant chose the interview location. One participant asked the researcher to meet her in a public educational facility located in Roanoke, Virginia, approximately 40 miles from Radford University. A private room was obtained in this facility and the interview was conducted in the setting as requested by the participant. Another participant asked to be interviewed in her private office at Virginia Tech, a public university. The remaining six participants agreed that Waldron Hall located on the Radford University campus was ideal, from their perspective, for conducting the interviews. All of the interviews were conducted in a room where privacy could be held in high regard to protect the confidential content of the interview.

The researcher began the meeting with each participant in the same way, by providing the background of the study and the study's intent. Each participant was given a detailed oral description of the interview process, as well as the transcription and analysis processes. The participants were then asked to read and complete the approved West Virginia University Consent Form (Appendix F) and the Health Insurance Portability and Accountability Act (HIPAA) form required by Radford University (Appendix G). All participant questions were answered prior to obtaining signatures. The participants were then asked to complete a demographics form (Appendix H). Demographics data included participant age, age at migraine diagnosis, intimate relationship status, pregnancy history, educational level, profession, health 
insurance status, and place of professional migraine care. Each participant received blank copies of all forms used to conduct this study.

After the participant signed the informed consent form, the investigator began the interview by first writing on a blank piece of paper 'the story of ...' (Smith \& Liehr, 2008, p. 217). The audio recording began with the researcher asking the participant, "What is it like to live with migraine headache?" The focus was initially on living with migraine in the present day. Smith and Liehr (2008) suggest that the story path focus on the past and then the future after gathering the story of the present day. The researcher maintained this present-past-future path of inquiry while attending to Van Manen's (1997) suggestion that the researcher stay with the original question throughout the interview. Van Manen further stated that with patience and silence the participant can stay with the original question. If the participant became idle, repeating the last sentence stimulated thought for her to proceed.

Each interview lasted approximately forty-five minutes to one hour. Data were collected over a three week period. The researcher focused on the woman as she told her story of living with migraines, while making notes related to body expressions and tone of voice of the participants as unobtrusively as possible. When necessary during the interviews, the participants were redirected back to the original interview question. The researcher asked clarifying questions to achieve this goal. At the conclusion of the interviews, each participant was informed that she would receive one or more follow-up e-mail(s) asking for confirmation, or clarification during the analysis phase. Each participant agreed to this request. Because data collection and analysis occur simultaneously in phenomenology, the recording of the interview, and field notes were reviewed immediately after each session. Additional notes were generated by the researcher as a result of this process. The recordings were then sent to the transcriptionist, who returned each 
recording and transcript within three days of the interview. The researcher then listened to the recordings while verifying the transcriptions.

Line by line analysis was completed for each transcript after the content was confirmed. Words and phrases which reflected the participant's experiences of living with migraine were brought to the margins of the transcripts. Eight recorded interviews and eight transcripts were obtained. It was evident that participant data had become redundant by the time the eighth interview was analyzed. Through consultation with faculty advisors, data collection came to an end.

\section{Data Analysis}

Various methods of interpreting phenomenological data exist in the nursing literature. For the purposes of analyzing the interviews of women in this study, van Manen's method was utilized. Van Manen (1997) believed that theme is the meaning of an experience. Theme is the form used to capture understanding. Theme allows us to make sense of that which we seek to understand.

According to van Manen, theme is a simplified formulation of the focus or point of an experience. To capture theme, van Manen (1997) suggested that the researcher first look at the text as a whole, asking the question "what does this mean?" and write a phrase that captures that meaning. Next, he suggested that after several readings, the researcher circle essential descriptions of the phenomenon of interest. Finally, each sentence is examined with the question “what does this reveal about the experience?" (Van Manen, 1997, p. 93) The task is then to determine commonalities (themes) and capture them with words. Finally, the researcher should ask if the phenomenon would lose its meaning without the theme. Researchers have a need and a desire to make sense of that which is not understood. Identifying themes from the 
phenomenological interview allows the researcher to grasp the essence of the phenomena, or "touch the core of the notion we are trying to understand" (van Manen, 1990, p. 88).

The researcher began each interview with an open-ended question aimed at eliciting the participant's story of what it is like to live with migraine headache. Each participant was invested in the telling of her story by actively expressing words that hold the meaning of living with migraines. The interview and simultaneous analysis, as well as additional analysis processes were conducted in a manner that is much like peeling an apple. The goal was to get deeper and deeper to the core of the phenomenon of living with migraine headache, yet each layer was recognized for its own value. Through asking "what does this mean?" and analyzing the data line by line, and through periodic consultation with faculty, each layer was fully understood and described before proceeding to the next step of analysis. Van Manen explained that the researcher arrives at the thematic core through three commonly used methods discussed above. Furthermore, as the researcher reflected on the transcribed interview, a focus was maintained on the four existential life world themes known as: lived space (spatiality), lived body (corporeality), lived time (temporality) and lived human relation (relationality). According to van Manen, all human beings experience the world in these existential themes (probably) (Van Manen, 1997). Further explication of this process is described in Chapter 5.

\section{Rigor}

The rigor of qualitative research is upheld through the establishment of credibility, auditability, confirmability and fittingness (Sandelowski, 1986). Credibility increases the confidence in the truthfulness of the data. In order to establish this credibility, the investigator engaged in the concept of prolonged engagement, meaning that this researcher invested a sufficient amount of time to develop a true understanding of what it is like to live with migraine 
headache. The researcher thoroughly engaged with the data during the interview process, again while listening to recordings and reviewing transcripts, during conferences reflecting on the data with various committee members, and during the process of building a structure of meaning.

The investigator also embraced triangulation to establish credibility. This was achieved by gaining data from three sources: the interview, observation of the participants, and the transcript and field notes related to the recorded interview. To further establish credibility, the researcher identified a nurse educator with a $\mathrm{PhD}$ to serve as an external check that confirmed or refuted the data by following the transcriptions as well as the notes and analytic interpretations generated by the researcher. Several conferences with faculty advisors served as an external check as well. Furthermore, participants served as a member check when the data was returned to them to verify the reconstructed story that was developed from the transcripts (Polit \& Hungler, 1997).

Auditability involves the establishment of a data trail. This trail is located in journal documents that the investigator kept throughout the research process. The journals include the notes the investigator maintained from the interview phase throughout the analysis phase and the interview transcripts that include each stage of the analysis notes. Each participant was assigned a pseudonym of her choosing and an Arabic number beginning with one (1). For example, the data for Participant 1, Mary, was labeled as: the recording Mary (1), the field notes Mary (1), the transcription and analysis notes Mary (1) and the follow up notes Mary (1). The purpose of this trail is to allow an experienced researcher to follow the same procedures as the investigator and arrive at similar conclusions (Polit \& Hungler, 1997).

Confirmability "refers to the objectivity or neutrality of the data" (Polit \& Hungler, 1997, p. 307). This implies that two or more people will review the data and agree to the data's 
meaning, eliminating bias. This was established through member checks, external checks and a well-developed audit trail (Polit \& Hungler, 1997). Fittingness or applicability, defined as the data fitting beyond the study, also come to light by verifying that participants relate to the data through the process described above and in Chapter 4 (Sandelowski, 1986).

\section{Summary}

This study brings to the literature an understanding of migraine from a woman's perspective. Using hermeneutic phenomenology and the nursing middle range theory of story theory as the philosophical underpinnings, the question that was explored with the participants was "What is the structure of meaning for women living with migraine headache?" The study included women who self-reported migraine headache and were over 18 years of age and could speak English. Van Manen's (1997) methodology of inquiry was followed during the data collection and analysis phases of the study. Story theory also guided this work (Smith \& Liehr, 2008).The participant interviews were transcribed verbatim and the investigator ensured the accuracy of the transcription. The investigator ensured that each participant's rights were protected throughout the study while conforming to the accepted standards of rigor for qualitative research. 


\section{Chapter 4: Presentation of Findings}

The purpose of this study was to develop a structure of meaning for women living with migraine headache. Eight women were interviewed over a three week period. The audio recordings and transcripts were reviewed simultaneously with field notes to gather a general sense of the meaning. Essential statements were identified to build a reconstructed story for each participant. After validation of the story was obtained from the participant, the thematic statements of each story were used to create the structure of meaning for women living with migraine headache.

This chapter presents the description of the participants, followed by an extensive description of the data analysis process and findings of this study. The analysis process is described in relation to van Manen's (1997) six activities to guide researchers in the collection and analysis of data, a simultaneous process. The structure of meaning for women living with migraine headache is presented and a rich description of the data supporting this structure is provided.

\section{Description of Participants}

Each participant selected a pseudonym to use in this study: Mary, Elizabeth, Zoe, Rachel, Meredith, Mandy, Brittany, and Sue. Demographic data were hand-tabulated following the completion of the interviews. All the women who participated in this study have health insurance, and seek care for migraine headache from either a primary care provider or neurologist. The participant's ranged in age from 18-62 years old. Each decade of life was represented among the participants. One participant reported her highest level of education as "high school," while the remainder of the participants held "college degree," three of whom held a "graduate degree." Four participants reported a previous pregnancy, but none of the 
participants were pregnant at the time of the interview. Those participants, who were able to recall when a migraine diagnosis from a healthcare provider was confirmed, reported that this diagnosis occurred at either age $3,11,12,16,17$, or 50. One participant was a full-time student and not employed. Two participants were full-time students with full-time employment. The remaining participants were employed full-time. Three participants were married or living with a partner, three participants were single and two participants were divorced or separated.

\section{Data Analysis Processes}

Data analysis began during the interview of each participant. The researcher listened intently as the participant spoke. While listening, the researcher took notes regarding the tonality of a statement, participant body language, and possible meanings of spoken phrases. To clarify the context of spoken words, the researcher often asked questions designed to elicit true meaning from the participants. The researcher then reviewed the audio tape after each interview to elicit further understanding of context and meaning.

As discussed in Chapter 3, van Manen (1997) described six interrelated activities which are designed to assist the researcher in the process of data gathering and analysis. These activities, along with the integration of story theory (Smith \& Liehr, 2008), allowed the researcher to dwell with the phenomena of interest. The outcome of these processes was a structure of meaning for women living with migraine headache with seven interrelated core qualities. Each of van Manen's suggested activities will serve as discussion headings.

\section{Turning to a phenomenon which seriously interests us and commits us to the world.}

This study was designed as a result of the researcher's interest in women who live with migraine headache. The data was gathered in a manner that suspended the researcher's presuppositions about migraine headache, assisting in the creation of a deep orientation to the research question, 
"What is the structure of meaning for women living with migraine headache?" This thoughtful approach yielded a structure of meaning with seven interrelated core qualities to be presented below. Individual interpretation of what it is like to live with migraine headache was generated in response to the question "What is it like to live with migraine headache?" in order to provide an understanding of women's experiences.

Investigating experience as we live it rather than as we conceptualize it. The participant interviews were conducted following both van Manen (1997) and story theory (Smith \& Liehr, 2008). Guided by story theory, each interview was an intentional dialogue focused on eliciting the participant's story regarding living with migraine headache. The question posed to the participants at the beginning of the interview was, "What is it like to live with migraine headache?" This beginning allowed the participants to reawaken their lived experience with migraine headache. As the experience came alive, the participant became aware of the body's relationship with headache, and their thoughts and feelings related to migraine. The researcher kept the focus on this experience throughout the interviews while asking questions to gain an understanding of what it was like to have migraines in the past, what the present headache experience entails, and the participant's perspective related to the future. Recording these stories allowed the researcher to capture the words as spoken. Interview notes maintained by the researcher provided observational insight in regard to body language and tone. Through the use of notes, journaling, and reflection with faculty mentors, the researcher was able to stay with the experience of living with migraines as described by the participant. The result was data that does not involve researcher tendencies or judgments.

Reflecting on essential themes which characterize the phenomenon. The search for themes began during the interview. The researcher kept notes of key phrases spoken by the 
participants. When necessary, the participant was redirected back to the interview question. As the story unfolded, the field notes and spoken words started to reveal the essence of living with migraine headache. The researcher began the analysis process during the interview by writing thoughts related to the phenomenon during the interview.

After each interview was transcribed, the researcher used a selective highlighting approach to isolate that which seemed to reveal something essential to living with migraine headache. These statements or phrases were rewritten in the margins of the transcripts. The researcher then went back to the recording to carefully confirm the context of the spoken words and create an extended understanding of the essences (Van Manen, 1997). This process also served as a method to confirm the accuracy of the transcription. The next step in the analysis process was to create a reconstructed story for each participant using her own words (Appendix I) from the core qualities identified in the transcript and recording analysis. These reconstructed stories were developed with a "beginning, a middle and end that highlight the core qualities situated in the storyteller's experience" (Smith \& Liehr, 2008, p. 37).

Describing the phenomenon through the art of writing and rewriting. Phenomenology is giving voice to lived experience. The deep tonalities of language require attention in order for the true voice to emerge (Van Manen, 1997). One method of understanding these deep tonalities was to generate field notes while conducting the interviews and engaging in line by line analysis of the transcription. This writing and rewriting process combined with discussions with committee members, led to the identification of the core qualities of living with migraine as described by the participants.

A second method of understanding deep tonalities was to write a story in order to succinctly fixate the feelings of living with migraine headache to the paper. Following story theory, the core 
qualities of the individual interview transcripts served as the foundation for each participant's story. After the first story for each participant was generated and discussed with committee members, the stories were rewritten by the researcher. The structure of the stories was confirmed by two faculty advisors and the accuracy of the stories was then verified by the participants.

Under the guidance of faculty advisors, the stories were then analyzed for additional core qualities, "critical moments, and turning points that contribute to the health challenge" (Smith \& Liehr, 2008, p. 215). The researcher began the analysis by asking, "What is this about?" The stories revealed core qualities about different aspects of living with migraine headache. As the researcher continued his deep engagement with the data, these qualities, each based on participant descriptors, began to naturally fall under headings that seemed to best categorize the statements (Appendix J). One hundred five statements in the language of the participants were grouped under the core qualities (a) when first experienced, (b) view of self, (c) headache experience, (d) moving through the headache and (e) getting through the day. Next, the participant's descriptions under each core quality were lifted to a higher level of abstraction. The interpreted meaning became the core qualities of the structure of meaning for women living migraine headache.

\section{Maintaining a strong and oriented nursing relation to the phenomenon. While}

conducting phenomenological research, the researcher may be tempted to become side-tracked. By doing so, analyzing data, and writing about the data may include preconceived notions that the researcher brings to the phenomena (Van Manen, 1997). To avoid becoming side-tracked, the researcher continuously reoriented back to the interview question and the research question. Reorientation began during the initial interview and continued until the results of the study emerged. At each phase of data analysis, the researcher would ask "Is this what the woman in the 
study said?" and "What is the context of these spoken words?" This created a strong orientation with the phenomena of living with migraine headache.

Balancing the research context by considering parts and whole. Van Manen (1997) warned that the phenomenological researcher may become so buried in the parts of the research process and data analysis that the purpose of the study may be lost. This study was born because a gap existed in the literature related to what life is for women living with migraine headache. Each step of the study proposal and process was carefully crafted to capture this phenomenon.

The purpose of the study was always at the forefront during each phase of this study. Because the research question guided each stage, a structure of meaning with seven interrelated core qualities that define the whole of the phenomenon of living with migraine headache emerged from the women who participated in the study. This structure and its core qualities serve as the findings of the study and are presented below.

\section{Study Findings}

The structure of meaning for women living with migraine headache that emerged from this study holds seven core qualities. Each of the core qualities is interrelated. No one component is sufficient in itself to embody the full meaning of what it is like to live with migraine headache. The researcher identified participant exemplars which best reflect each component of the structure. A rich description of the data using these exemplars is presented below.

The structure of meaning that emerged from this study is: Living with migraine headache is: (a) recalling the significant experience that reshaped life; (b) experiencing self as vulnerable, with unmet expectations, unfulfilled relationships, and regrets; (c) being overcome by unrelenting, torturous pain magnified by intrusion from the outside world; (d) pushing through to hold self together to do what needs to be done, in spite of torturous pain; (e) surrendering to the 
compelling call to focus on self in order to relieve the torturous pain; (f) making the most of pain-free time to get on with life and navigating the aftermath of the headache experience; and (g) being on guard against an unpredictable attack and yet hopeful that it is possible to outsmart the next attack. Each component of this structure of meaning will be discussed further and include participant exemplars which illuminate the essence of the component and the structure of meaning as a whole.

Recalling the significant experience that reshaped life. All the participants indicated a point in their life when the migraine headache began. In addition to the pain, the participants began seeking care from healthcare providers, taking medications, and experiencing an altered life because of the headaches. All but two of the participants stated the onset of migraines began during the teenage years. The words of Brittany describe her experience of being a teenager new to migraine headache:

Yes my mom used to tell me when I would have a migraine, if I had a migraine on one day that I could miss school. The next day I still didn't feel that great. She would be like, well you don't have to learn anything in school you just have to go and be there. They had a big strict attendance policy. So I would go. I'm sure I didn't learn anything the days that I was there. You know. There were times I slept through class. I would, I would sit down and sort of just be in a daze. I, but you know, I was there; I was just doing what I had to do to get through the day.

Only one woman, Elizabeth, could not remember when the migraines began:

I don't really remember when I was, you know, 2 and under, but my parents think that the first time I had a migraine was with the very first night they left me alone at night. I stayed with my grandparents when I was eighteen months old. And my grandmother never called them, but the next day when they picked me up she told them that I been vomiting all through the night and at that point they didn't know it was migraines. But later on that's what they assumed it was. 
Rachel lived with headaches from her teenage years through surgical menopause. After menopause, her headaches decreased to a point of absence, but a new migraine condition emerged:

I had a hysterectomy when I was 50, which put me in, you know, total menopause. And I had an oophorectomy. I had my ovaries removed at the same time. So I was in immediate menopause, surgical menopause. And I, then for a while, I didn't really have migraines, or not, not very frequently anyway. So that was a relief. I was thinking, wow, they, you know, I had, I had this hysterectomy because I had fibroid tumors that were causing really severe bleeding, and I was very anemic at the point that I was diagnosed with fibroids. So, I said wow, this hysterectomy has done two good things for me. (Laughs) I'm not, I'm not bleeding all the time, I'm not, I'm not having migraine anymore. And I was like, pretty ecstatic. But, then, I started getting other kinds of migraines that started more with an optical aura. And they were very different, they've been very different since, you know, since I've been postmenopausal. And... that was very frightening at first because I would get this, this bright, you know this bright ark in my eye and I couldn't see well. It was always in one eye. And it would start when, usually when I'm very tired. And I first thought, well I've got a brain tumor or you know something really serious. So I ran to the ophthalmologist and he said 'no, you have migraine' (laugh) it's, it's just a migraine aura. And he said check it out with your doc, but it's that's probably what it is. It's not anything really serious. So, that made me feel a lot better, but they were, there's still a problem when I have them because I can't see well.

Overall, the participants indicated that a significant change occurred in their life when the migraine headache started. The stories of these women suggest that fear, unknowing, and the process of gathering the courage to move on with life accompanied the onset of migraine headache. In general, the participants adjusted their lifestyle in an effort to manage the new illness that had entered their life.

\section{Experiencing self as vulnerable, with unmet expectations, unfulfilled relationships,}

and regrets. Overall, the participants described the feeling of vulnerability when speaking about living with migraine headache. Although migraine is the overshadowing reason for this feeling, the participants revealed that seeking relief for migraine headache often leaves them feeling helpless. Sue indicated that the emergency room is often her only recourse for relief and that her 
numerous visits to healthcare providers contribute to her sense of helplessness related to

migraines. Mary described it this way:

One of things for all health care providers who work with women who have migraines, we want to be taken serious and it's not just, that were tired and whiney and don't have anything better to do than complain about our ailments. It's... it's difficult to live with these headaches and when we're seeking relief, you know, we just want to be heard and a lot of times I feel like that it... it just gets pushed to the side. There's no test to say that this is going to work for your migraines so this is what you need. It's, you know try this, but if it doesn't work what do you try next? Because you don't want to keep going back to the doctor, you know? I've got a migraine. Well, you can't get a sick visit for a migraine, you know you got to call back and get the appointment in two months for a migraine. Well you don't have a migraine in two months. So, and then you've forgotten how you felt when you had it. And, I, none of the medicines I have ever tried ever worked and that's frustrating to me but I'm still left with nobody's doing anything about it.

Another woman, Mandy, describes her feeling of vulnerability when speaking of a time

when she had hoped for a cure for migraine headache:

I think at one point I was optimistic because you know, I had the surgery [total hysterectomy] you know, the doctor, the Neurologist had said you know this is a good thing we'll move forward. I think at that point I was optimistic that you know it's a good thing. We're headed towards things getting better. After going through that period of coming off the medication and realizing that it wasn't what we hoped it would be, I think at, I'm at the now where I'm just kind of...I don't really know how to put it. I guess I'm just kind of resigned to this is just the way it's going to be. Suck it up and live with it.

The notion of unmet expectations for self was prevalent in the stories of the participants.

Overall, the participants described themselves as women with strong work ethics and holding the desire to succeed in all aspects of their lives. Unmet expectations are noted in statements like "I am just a body at work" and "I just feel so miserable I don't care what needs to be done" when a headache is occurring. Mary describes the impact migraine headache has on her ability to be successful in her work, school and home life:

I always give everything $100 \%$ of all I can. And I don't like not being able to do that. I guess that's probably the root of the problem is when I can't, when I've got a migraine I know that I can't give $100 \%$, and that bothers me. I'm not able to perform at the top of 
my game all the time, and when you can't, it's not that, you know, I stayed up too late the night before, it's you know, you got the migraine and can't focus, you can't be as bright and chipper as you can usually be. And I like to be a pretty positive person. I don't like to have negative emotions or think poorly about the day, but when you're feeling that bad it's kind of hard not to. And to project that on other people, that's another thing I suppose is, that I don't like to project a negative attitude towards others because I think others pick up on that. And it brings everyone else down. it's hard sometimes because, especially you know, I guess that I'm a perfectionist type person and since I've got that kind of personality, when I again, I keep saying the same thing, when I can't do everything I want to do at the best I can do it, that's disappointing for me. And when I, again going back to projecting on other people, if, you know, the people around you feel like they can't, you know when my kids can't scream in the house cause momma's got a headache, you know, I don't like that either. I like for them to, you know, be kids and um, and then you can't enjoy the things in life. If you're at a soccer game for the kids, but you've got a headache and the sun is beating down on you and you want to scream for your kids but every time you scream it feels like your heads going to explode.

The feeling of unfulfilled relationships emerged from the participants stories. Migraine headache impacts relationships with significant others, children, friends, and colleagues.

Meredith stated that she feels as if some of her colleagues at work believe that she is "faking" the headache to avoid work or another event. Sue relinquished care of her children to her husband, creating a sense of damaged relations with her family. An example of how migraine headache created an unfulfilled relationship is found in the words of Mandy who speaks about her relationship with her son during the migraine:

It's very difficult because as the mother you are the primary care giver and it's very difficult to think that there are times when you can't take care of your child. But, not only can you not physically care for your child, suddenly their taking on that role as a caregiver for you. I mean it's sweet to know that your child thinks that much even at a young age to want to do that. But at the same time it's very difficult to think that, you know, here I am, I can't take care of my child. I can't even take care of myself at this moment. And here he is you know wanting to take care of you. It's a very difficult, a very difficult feeling to adjust to.

Another example comes from Elizabeth who talks about the unfulfilled relationships with others when she is in the midst of a headache: 
I think really the main things that my parents and other people that was taking care of me at the time for migraines are the ones to not get, you know, upset if their feelings hurt if I say something that I wouldn't say something hateful, but I just wouldn't be very accepting of their help or excited about helping others. You know, like I said before, I don't want to hear anybody talk.

The participants revealed regret for being subject to living with migraine headache.

Rachel enjoyed bearing children and breastfeeding her offspring, but she questioned why she is a woman:

It was like, what more do I have suffer? I mean the whole thing is, I guess feeling like why am I a woman? You know, why did I have to be a woman? Yeah, it was great having kids and breast feeding them and everything. But, it was all this other stuff that I don't like to deal with.(Laughs) I'm not having any more kids so why do I have to keep suffering through all this these menstrual cycles and migraines?

Zoe expressed regret for living with migraine headache. Like the other women in her family, including her mother, she experiences the pain of the condition. Because of her childhood experiences of watching her mother in such pain, and because of her own experiences with migraine headache, Zoe has decided to not have children. She stated:

Well, because of the migraines and some other, other issues that my mom has passed on, that have been passed onto me because of my mom's like, heritage and genes and all that. It's been passed onto me. Like, my brother doesn't get migraines. He doesn't have like any of the effects. He doesn't get anything that I get that I got from my mother's side of the family. So, I would never want any of my children to go through this.

Migraine headache contributes to feelings of vulnerability for the women who participated in this study. These feelings are evident when seeking care and treatment for the headaches. Unmet expectations for self are prevalent throughout the stories of these women who long for independence from the suffering. These women experience relationships that are unfulfilled because of the pain and associated physical conditions related to migraine headache, 
and because of the need to focus on for self when the migraine strikes. Living with pain and suffering is something these participants regret about their lives.

\section{Being overcome by unrelenting, torturous pain magnified by intrusion from the}

outside world. Participants in this study described the pain related to migraine headache as torturous. The "torture," as stated by Mary, involved a feeling of increased pressure in the head. Sue further described the pain as a "freight train coming through." Brittany said the pain was like "A storm entering my head." The remaining five participants reported feeling as if their head would "explode."

Even though the pain eventually diminished, the participants felt that the pain would never go away during the intense moments of the attack. The migraine diminishes the women's ability to concentrate. Voices and external sounds echo throughout the head, compounding the pain experience. Zoe describes living with the pain and the associated symptoms:

Luckily I don't sick. I know some people that get very sick from them [migraine]. Mine is just, I'm really sensitive to light, I am very sensitive to noise and my lovely dog likes to run around when I have migraines. But, I just shut myself off from the world. At least I try to as much as possible. Sometimes I'll put a wet washcloth or an icepack over my head. For like, just like the last migraine I had, it literally, like, for a while there the, you know, having the icepack would help and like, I'd put a ball cap on. If I ever go out I'll have sunglasses, even if it's like raining outside. But sometimes the pressure comes, like the pressure from the ball cap or from having an icepack or washcloth over my head just kills me as well. So, it's, it's just like a battle. You're, trying everything, every like hour or so to decide ok, is it going to, what's going to work well and what's not? But, by that time I've usually tried to get [help], gone to some kind of doctor to make it stop.

The intrusion from the outside world for the participants includes voices and external noises. During the interview with Zoe, construction noise was echoing into the interview room. Her response to that noise was "hearing that all day would kill me." Sue describes the voice of another during a migraine as "a stereo and someone just keeps turning the volume up in my head." She goes on to describe sounds in a room as "echoing through my head. You can just pick 
up that pencil over there and when you have a migraine, you could actually know that you just picked up that pencil." Mandy verified this by describing the sound of another person's voice as "fingernails on a chalkboard." Elizabeth further described the impact the outside world had on the pain:

It usually messes everything up [slight laugh] because I really can't, I can't do any work, I sometimes can drive, but usually if I'm around people who know me and know that I get migraines say, seem to think that I'm not, I guess, well enough to drive I guess I've been out of it kind of.... So, that I definitely had run into that, some people and I was going to this place and I wanted to go home and someone actually made me ride with them home because they didn't feel like I was capable of driving. In my mind I thought I was, but I guess on the outside I didn't appear to be. My school work definitely I, just I can't focus. It probably just makes my head hurt worse if I try to do some of that while I have a migraine.

Further intrusion from the outside world arrived in the form of light. Zoe stated that the

light forces her to wear sunglasses, but the sunglasses create a feeling of more intense pressure in the head. Intense pain and sensitivity to light and sound related to migraine headache was a prevalent core quality throughout the stories of women living with migraine headache. The inability to focus on the task at hand during the attack appeared in all of the transcripts.

\section{Pushing through to hold self together to do what needs to be done, in spite of}

torturous pain. The women who participated in this study spoke of pushing through the pain to meet the expectations held by themselves and others. They described their roles to be: significant other, mother, sibling, daughter, student and employee. Mary discussed the idea of pushing through the pain to accomplish as much as possible related to her many life roles as a woman:

...because you know you've got so much you got to get done even with the headache and have to push through it. Frustration, because often times there's nothing you can do to stop it from coming when you feel it coming, a lot of stuff I haven't never thought about,(laugh) feelings wise, with what you're going through. 
Meredith discussed the idea of pushing through from a different perspective. She

described a particular instance when others knew she was ill because of her bodily expressions.

She was in a lot of pain, but wanted to push through for the sake of her friends:

It was just summer on asphalt at a theme park. So, everyone else is having a great time they're not even hot at all; they think it's wonderful and I am red faced sweating like crazy because I feel so bad. But, I'm trying to just ignore [the pain] and act like everything's fine and I'm just like I can do all these things and then it got to the point where I just had to stop. I had to sit down, get something to drink. And the people are having to wait on me and go get me drinks and paper towels. And it, it is embarrassing because they didn't really know what I was going through. They didn't understand how difficult it is. At that point I had not learned that I need to keep my medicine with me always and um, make sure I have plenty to drink. And I'm sure it's different for everyone but, there are certain things that you can do, or I can anyway.

The women in this study described the struggle of meeting many expectations when in severe pain. This struggle includes making the decision about staying at home when in pain, or pushing through the pain to accomplish that which cannot wait until the migraine subsides.

Brittany described going to work in order to meet the demands placed on her:

If I have too much going on that day and I feel like I can't call in sick or I can't go into work a few hours late um, I have to suck it up and go. It might involve you know, just taking medicine throughout the day, drinking lots of water and, caffeine (laughs) sometimes will help. But, you just have to go on through it.

\section{Surrendering to the compelling call to focus on self in order to relieve the torturous}

pain. The participants in this study want to meet all of the demands placed upon them as women, even when experiencing pain. However, there comes a point when the woman with a headache must stop what she is doing to focus on herself in order to gain relief. In addition to relinquishing responsibilities and chores, this focus on the self may include taking medications, making an attempt to retreat to her bed, or seeking the support of another who has experience with assisting to her achieve relief of the migraine. Zoe describes her experience of focusing on self: 
I remember when I was having, when I was, I was in the middle of the long migraine. And , I remember coming home one day and my dog had, he hadn't been out for, he had been in his crate for a lot longer than he was use to and. I remember, he like, you know, he wanted to go outside and, he just like, started peeing and instead of like getting upset about it I was just in so much tears. Because I was like there is nothing I can do to help you. I'm like, I'm trying the best I can, I'm like, but, (laugh). And that was the only time that I was just like, like I called my mom and I was just like you need to come, I need a babysitter right now. Cause there's no way I can handle taking care of him the way he needs to be taken care of.

For many of the participants, the intensity of the migraine headache will drive them to

bed, where their focus is only on them. This bedroom environment, described by two participants

as a "cocoon," may include cold temperatures, a damp wash cloth to the forehead, and curtains

that are drawn to block the outside light. Meredith described the bedroom environment and

medications that bring her relief:

I do like to crank down the air-conditioning. I like to make it as cold as possible so when I lay my head on the pillow it's like an ice cube. (Laughs) I mean, not literally, but just very cold to the touch where most people wouldn't be comfortable, they'd be freezing. Sometimes I'll get a wet washcloth um, so that it's good and cold um, and lay that across my face. Sometimes it's just one side of my, my face um, that hurts. Like below my eye or above my eye and so I'll lay the washcloth on that side because the other side doesn't, doesn't hurt as bad. But, I do like for it to be cold. That is one the main things that helps me. I don't like humid like warmer climates. I really like it here, (laughs) and so I do like to go to the beach. But I would not ever want to live there because I feel like it would just be a constant pain.

Two participants, both with small children, painted a different picture when speaking about relinquishing responsibilities to focus on themselves. Because their children required supervision and assistance with daily living, these two participants focused on themselves while simultaneously focusing on the children. Rachel spoke about an experience with her young son:

Well, sometimes I, I mean sometimes I had to [go to bed]; I just had to because I was just so wiped out, and I did. I mean sometimes it meant literally taking kids to bed with me. And, I can remember, (laughs) and don't think that I'm a cruel mother because I wasn't doing this in any kind cruel way, but with my first child who was very, very active, I can remember kind of hugging him in bed with me so he would stay still and go to sleep because he was, he didn't like to nap much. This was when he's pretty little even. And, 
and, if I could hold him still for a little while he would fall asleep and then I could sleep you know? And, and if I had a migraine or something that was really important for me. My other children, I didn't require so much strong arm tactics. (Laughs) if you can call that strong arming. I mean, it was done in a loving way.

The participants all realize that in spite of pushing through the pain, the time will come when they need to focus only on themselves. Focus involves many different strategies to find relief, including taking medications, going to a cold dark room to eliminate all external stimuli, and resting as much as possible. The stories revealed that the focus on self is truly individualized, and may include keeping children safe while focusing on self.

\section{Making the most of pain-free time to get on with life and navigating the aftermath}

of the headache experience. The women who participated in this study spend pain-free time picking up the pieces from the preceding migraine experience. These women use the pain-free period to engage in activities such as exercise and stress reduction in an effort to prevent the occurrence of migraine, or to reduce the frequency of headaches. In addition to the acute pain and associated symptoms that accompany migraine headache, the stories from the study revealed that migraine headache has a significant impact on the body beyond the acute pain period.

Mandy likened the post-pain period to recovering from the flu. After the pain subsides, there is a feeling of fatigue and weakness:

I mean if you have a migraine that lasts you know, a couple days you're in bed for two days, you don't eat. It's all you can do to keep fluids in you because you, I mean you honestly don't feel like moving. So, I mean, you haven't ate, you've barely drank. You've probably have barely slept for two days because the headache will literally keep you awake no matter what you try to do. You know, unless you're fortunate enough to find something that works for you that you can take and won't, will help you sleep it off. And even when you're, you do sleep the pain's still there so you're not sleeping well; you're not getting that REM restful sleep. So, that's two days of no food, no liquids, no sleep, no rest. So basically it's like any other illness that you have and then you, you have to recover from that. 
Missed events and time spent with family and friends induces a feeling of guilt for some of the women in the study. Much like a thief in the night steals something of value; time that these women have to enjoy life is often taken by the migraine headache. The women in this study reported using pain-free time to "mend fences," as stated by Mary:

The good things are certainly that you don't have a headache, but sometimes during that inactive phase you're actually getting over another one and so you're trying to recoup, and sometimes redo things that you have done halfway, while that active phase was going on, whether it's you know, you might have vacuumed the floor, but didn't vacuum it as well as you would have, or you know, whether it's going back and mending some fences that you feel like, you know, you just didn't do what you normally would do. Especially with kids because they pick up on it that mommy's not feeling good. I don't want them to ever feel like it's their fault that I'm not feeling well, that they've not been good enough kids or whatever, but, I try to take those inactive times to really enjoy, enjoy life because I guess that's just the kind of person I am.

The other participants confirmed the words of Mary when asked about mending fences.

They each agree that "mending fences" involves redoing work to a higher standard, taking on extra work during the day to catch-up on that which did not get done during the pain, and making up for lost time with friends and family. Mandy said that she understood how her boss and coworkers would be frustrated when she misses work. Mandy summed up the experiences of "mending fences" when she spoke about how much she does when not experiencing a headache, "I'm working 60 hours for the job here plus trying to do everything with my kid and making sure he's not missing out on any time that he should have."

\section{Being on guard against an unpredictable attack and yet hopeful that it is possible to}

outsmart the next attack. The women in this study describe a core quality that emerged as the unpredictable migraine attack. The migraine that can be predicted, such as those that occur at the onset of menses, seem to be more tolerable than the migraine that occurs without warning. One participant stated that she can "prepare for it" when she is anticipating menses. Another 
participant said that she has cannot "prepare" herself for the unanticipated migraine. This notion was described best by Meredith when she said "they [unanticipated migraines] usually interrupt something that you want to be doing that you... you're in the middle of something and then wham." Meredith described the impact of the unpredictable attack:

I think that the one's that come out of the blue usually interrupt something that you want to be doing that you, you're in the middle of something and then wham! The ones that you kind of feel their coming, or have an inkling that you're going to have a migraineYou can plan for it. Um, you certainly cannot plan on every one of them. But, I think the ones that hit you out of the blue are the most hard for me to deal with anyway because it usually interrupts something.

A significant core quality found in the stories of these participants is the attention that is given to trying to avoid the attack of migraine headache. Headache triggers are addressed in the pain-free period, including engaging in activities which decrease the physical and emotional stress that the participants identified as a significant contributor to headache. A common problem for these women is the inability to fit the stress reduction activities into the demanding schedule of work they have on any given day. The words of Zoe capture the significance of reducing stress during the pain-free period:

If I can have stress out of my life I would do it in a heartbeat. I think my problem is that, most of the time, like I usually, I work out regularly every, pretty much every day. And I've noticed that when I'm working out it handles, you know stressing, it handles the stress a lot. But, I know the two incidents [severe migraine] that I've had. Like the first time I had the incident, there was a... and it was full a very long day. I had just taken a full load [course work]. I had just taken 21 credits in the Spring, I had taken a full load that Summer, and I was also working and doing internship. And it was just, I, I didn't realize I was building it. And then it [stress] just kept going and kept going and kept going. And finally it exploded and not only did I get the migraine, I had shingles which at twenty, I was 22 at the time and having shingles cause I know you're supposed to have them at like 70 ! Kind of, kind of worried me a little bit. 
Stress was commonly discussed by all of the participants as being a significant trigger for migraine headache. Not all participants realize that stress is mounting in their bodies to trigger a migraine, but Rachel spoke about the known impact that stress has on her:

You know the stress of teaching will bring one on too. Oh, it's enormous. I have had to stay up late grading, and then students are not happy about something. And that's when I will get a migraine, you know. But, it's not the unknowingness at this point, it's not, I mean it's pretty predictable when I am abusing myself. Not getting enough sleep you know. And, and it's kind of strange because too much caffeine use to bring it on. But, now it might be just more that I'm not getting enough sleep and I'm drinking a lot of caffeine.

Elizabeth spoke of the importance of strong relationships with family and significant

others in addition to exercise for keeping stress at a minimal level:

That's usually the people I turn to if I am stressed. I go to my family or my boyfriend and his family, so, we, we have a very strong relationship. So, that's kind of my stress reliever I guess. But, my, mom and I, sometimes we, especially when I'm home in the summer, we do Yoga sometimes and that relaxes us both, but I would never motivate myself to do that while I had a migraine. But, I definitely think that probably relived some of the stress that I had.

The participants identified common and unique things that might trigger migraine headache. Common triggers in addition to stress include specific foods such as chocolate and coffee, and menses. Sue recently discovered that cinnamon is a trigger for her. Meredith reported "heat, a stuffy nose, any head illness, and a tense neck" as triggers. Elizabeth has learned that cold weather is a trigger for her. Brittany stated that any change in the weather triggers migraine headache. Mary, Zoe, Rachel and Meredith identified "long days" as a trigger for migraine headache.

The data revealed that the participants want control over their bodies, and may think they are able to outsmart both the anticipated and unanticipated headaches by avoiding triggers. The participants also engage in behaviors that bring joy to their life, such as reading and playing, in 
hopes that this too will prevent a headache attack. Being well prepared with medications to stop the pain early in the process also emerged as a way of trying to outsmart the attack in the study. As noted by Meredith:

I try other methods of getting rid of it [headache] before I take my pill um, because my insurance doesn't cover. My insurance will pay but only if I get it through the mail. So, if I if I run out, and get a migraine I'm kind of stuck because I can't just go to the pharmacy and pick one of my migraine pills. I have to wait for it to be approved, and it's such a hassle and usually the doctor has to contact the company. Then I get a six pack, six packs of those in the mail. So, on top of having a migraine you find out you don't have any medicine left and you have to contact the doctor and the company, it's not a lot of fun. So, I'm trying to stay on top of that, but I always have one in my purse. I try to keep some in my office and at home. I try to leave one at my parents' house so if I'm there and for some reason don't have it. That has all been just based on experience. I've gotten somewhere and not had one[pill], and that's the worst feeling is getting somewhere knowing that what you need to really take care of it [headache] you don't have [medicine].

Unpredictable migraine attacks emerged as a source of stress as the women in this study told their stories. The women in this study are generally aware of what triggers their migraine headache. They strive to be on guard against the migraines by reducing those triggers, especially stress. Keeping medications close by is one attempt described as an effort to outsmart the headaches. A woman with a lot of migraine experience, Sue summarizes the idea of being on guard by saying that "if you do not want to suffer then you don't do what causes you pain."

Many of these participants, including Sue, occasionally identify a potential new migraine trigger that they must deal with in their efforts to outsmart the headaches.

\section{Summary}

The research question for this study was "What is the structure of meaning for women living with migraine headache?" Van Manen's work and story theory were used as the framework for data collection and analysis. The interviews and recordings were analyzed for themes. These themes were used to create a reconstructed story for each participant. The 
thematic statements from the reconstructed stories served as the foundation for the development of a structure of meaning for women who live with migraine headache.

The structure of meaning that emerged from this data is: Living with migraine headache is: (a) recalling the significant experience that reshaped life; (b) experiencing self as vulnerable, with unmet expectations, unfulfilled relationships, and regrets; (c) being overcome by unrelenting, torturous pain magnified by intrusion from the outside world; (d) pushing through to hold self together to do what needs to be done, in spite of torturous pain; (e) surrendering to the compelling call to focus on self in order to relieve the torturous pain; (f) making the most of pain-free time to get on with life and navigating the aftermath of the headache experience; and (g) being on guard against an unpredictable attack and yet hopeful that it is possible to outsmart the next attack. Chapter 5 discusses implications for nursing resulting from this work. 


\section{Chapter 5: Discussion}

The purpose of this study was to develop a structure of meaning for women living with migraine headache. Using hermeneutic phenomenology as described by van Manen (1997) and the nursing middle range theory of story theory (Smith \& Liehr, 2008) as the philosophical underpinnings, the question explored with the participants was, "What is the structure of meaning for women living with migraine headache?" As noted in the previous chapter, the structure of meaning for women living with migraine headache is: Living with migraine headache is: (a) recalling the significant experience that reshaped life; (b) experiencing self as vulnerable, with unmet expectations, unfulfilled relationships, and regrets; (c) being overcome by unrelenting, torturous pain magnified by intrusion from the outside world; (d) pushing through to hold self together to do what needs to be done, in spite of torturous pain; (e) surrendering to the compelling call to focus on self in order to relieve the torturous pain; (f) making the most of pain-free time to get on with life and navigating the aftermath of the headache experience; and (g) being on guard against an unpredictable attack and yet hopeful that it is possible to outsmart the next attack. The purpose of this chapter is to discuss the structure of meaning for women living with migraine headache in relation to the existential lifeworlds as described by van Manen, literature related to suffering, story theory, and its significance for nursing. Lastly, implications for research, practice and education will be offered.

\section{The Existential Lifeworlds}

Van Manen (1997) describes four existential lifeworlds: lived space (spatiality), lived body (corporeality), lived time (temporality) and lived human relation (relationality). Lived space, or spatiality, is the space that is felt. Space affects the body and emotions. Lived body (corporeality), is a reference to the fact that we are always in our body which may consciously or 
unconsciously reveal or conceal our truth. The loving or judgmental gaze from another impacts the decision to reveal or conceal truth. Lived time (temporality) refers to subjective time and is composed of the past, present and future. The past may have helped shape what we are doing today and our perception of what the future may hold. The future is influenced by the pressures of the present. Lived human relation (relationality) refers to the sharing of interpersonal space with others. Van Manen suggests that these four existential lifeworlds can be differentiated but are related.

Lived space (spatiality) includes the importance of space on the physical and emotional aspects of a person (Van Manen, 1997). One of the core qualities of the structure of meaning is surrendering to the compelling call to focus on self in order to relieve the torturous pain. The data which supports this core quality revealed that women living with migraine headache prefer to retreat to a private space that is often a cold, dark bedroom with the covers over their head. This ideal space for focusing on self is described by two participants as a "cocoon." When experiencing a headache outside of this preferred space, the external environment often contributes to increased pain and pressure in the head as noted in the core quality of being overcome by unrelenting, torturous pain magnified by intrusion from the outside world. The increased pain and pressure in these settings may be the result of the need to concentrate on the task at hand, environmental noise, the sound of another's voice, or the natural or artificial lights found in various settings. Another core quality of the structure of meaning is being on guard against an unpredictable attack and yet hopeful that it is possible to outsmart the attack. Three participants described how they are on guard for migraine triggers in outdoor spaces, including temperature extremes and changing weather patterns. 
Lived body (corporeality) is defined as concealing or revealing truth through the body (Van Manen, 1997). A core quality of the structure of meaning is pushing through to hold self together to do what needs to be done, in spite of torturous pain. The women in this study provided descriptions of hiding the bodily torment of living with migraine headaches. One method of hiding pain is to "keep on smiling." To show suffering often stimulates unwanted pity, or references to bodily appearance from another. Additionally, women with migraine may not want to project negativity upon others, provoking a desire to hide that which is being truly felt in the body. The women in this study indicated that when pushing through the pain and suffering is no longer possible, they retreat to a place of comfort and may allow others to help take care of them. These qualities are illuminated through surrendering to the compelling call to focus on self in order to relieve torturous pain.

Lived time (temporality) is described as subjective time composed of the past, present and future (Van Manen, 1997). The first core quality of the structure of meaning is linked to time. Living with migraine headache is recalling the significant experience that reshaped life. The women in this study, with the exception of one, recalled the time when life was changed because of the onset of migraine headaches, or when the migraine changed location in the body. The second core quality, living with migraine headache is experiencing self as vulnerable with unmet expectations, unfulfilled relationships and regrets, contains data related to both past and present. The women revealed that the timing of migraines impacts all aspects of life, often leading to regret and strained relationships with others. Past experiences of living with migraine headache have created the potential for a future without children for two participants. In spite of some participants feeling that the future does not hold promise for an improved life, all the participants revealed a hope to outsmart future migraine headaches. 
Lived other (relationality) is defined as the relationship maintained with others (Van Manen, 1997). Three core qualities of the structure of meaning are related to the concept of relationality: Living with migraine headache is (1) being overcome with unrelenting, torturous pain magnified by the outside world, (2) making the most of pain-free time to get on with life, and navigating the aftermath of the headache experience, and (3) experiencing self as vulnerable, with unmet expectations, unfulfilled relationships and regrets. The women in this study indicated that being judged by others when a migraine headache occurs intensifies the suffering that must be endured. Interacting with others involves concentration that may further intensify the pain. Further, there is a sense of "help me but leave me alone" when the women spoke about those who offer to assist during the attack. The women in the study indicated that the most productive relationships occur with those who intuitively know when to speak, and what to do to help. They revealed that "mending fences" with others is often part of navigating the aftermath of the preceding migraine attack.

The structure of meaning for women living with migraine headache that emerged from this study is linked to the existential lifeworlds described by van Manen (1997). The existential lifeworlds offer a framework for further understanding the structure of meaning of living with migraine headache. Lived space, body, time, and human relationships are embedded throughout the findings of this study.

\section{Suffering}

Kahn and Steeves (1986) offer a theoretical definition of suffering which includes the statement, "Any threat to personal integrity, whether painful or not, can invoke suffering" (p. 626). Threats to personal integrity invoking suffering are evident throughout the core qualities of the structure of meaning of living with migraine headache. The women in this study 
described the suffering related to pain as "tortuous," a "storm," and "like a freight train coming through." Each participant offered a vivid description of the torturous pain that is often accompanied by other symptoms such as, nausea, vomiting, insomnia, and the inability to tolerate food or drink. The body suffers due to the pain experience, but the women in this study also suffer from emotional distress caused by living with migraine headache. The participants revealed that judgment from others related to migraine headaches impacts work and social responsibilities, invoking further suffering. Furthermore, the women in this study each stated that they hold high expectations for themselves. Another source of emotional and mental suffering is found in the participants' inability to meet these self-expectations because of the need to prepare for the next migraine headache, the pain of migraine headache, and the need to navigate through the aftermath of the headache.

This study indicates that women with migraine headache endure physical, mental and emotional suffering. Morse (2001) holds that enduring suffering is a process of blocking emotional response to get through the day. She goes on to state that the act of enduring may manifest physically as lack of facial expression, unfocused eyes or speaking in monotone (Morse, 2001). As reflected in the core quality, pushing through to hold self together in order to do what needs to be done in spite of torturous pain, the women in this study described strategic measures which allow them to get through the day. These measures included "pushing through" the pain to accomplish all that must be completed. Even though participants "keep on smiling" to get through the day, behind the smile is often intense physical and emotional suffering. The participants in this study indicated that the primary desire during the migraine attack is to retreat to a space that allows the emotional release necessary to begin the healing process. 
Flaming (1995) reported that people bear suffering by “dealing with it” (p.1123). The findings of this study indicated that women have to deal with both anticipated and unanticipated suffering. The core quality, being on guard against an unpredictable attack, and yet hopeful that it is possible to outsmart the next attack, is a way to bear suffering by dealing with it. The headache that arrives unexpectedly creates uneasiness and suffering for the participants in this study. To outsmart this unanticipated suffering, the women described strategies such as avoiding migraine headache triggers, avoiding stress, and incorporating relaxation. Furthermore, being on guard for the next attack may require women with migraine headache to strategically maintain a supply of medication in numerous places to have on hand when the headache strikes. Dealing with the unexpected migraine headache invokes a form of suffering that includes the anxiety of always needing to be on guard as well as experiencing physical pain.

Ferrell and Coyle (2008) provide a schema of tenets related to the nature of suffering. One tenet is that "suffering is accompanied by a range of intense emotions including sadness, anguish, fear, abandonment, despair and a myriad of other emotions" (Ferrell \& Coyle, 2008, p. 108). A core quality of this study, experiencing self as vulnerable with unmet expectations, unfulfilled relationships, and regrets, represents the intense emotions associated with suffering. The women in this study described fear associated with the pain and symptoms of migraine headache. They also talked about being frustrated with others' inability to understand the different elements of their migraine experience. Frustration with obtaining caregiver appointments and medication was evident. A sense of helplessness became clear as the analysis process unfolded. This helplessness is related to the participant's inability to control the frequency and intensity of the migraine attacks. Sadness was evident as the participants spoke of lost time with friends and loved ones because of the migraine headache. Anger emerged in some 
descriptions prompting questions like "Why am I a woman?" when describing migraine headache and a dysfunctional menstrual cycle.

The structure of meaning provided a rich description of the suffering endured because of migraine headache. The pain that accompanies a migraine headache is torturous, and contributes to the body becoming weak from lack of food and drink. Suffering is best endured by retreating to a place of comfort which allows the emotional release necessary to begin healing. Suffering is evident in each core quality of the structure of meaning of living with migraine headache. The most prominent form of fear for women in this study emerged as fear related to the unanticipated headache and the suffering it may bring.

\section{Story Theory}

"Story theory is based on three interrelated concepts: (1) intentional dialogue, (2) connecting with self-in-relation, and (3) creating ease" (Smith \& Liehr, 2008, p. 209). Purposeful engagement through intentional dialogue with another is the method employed to summon a complicating health challenge such as migraine headache. A trusting relationship was established between the participants in this study and the researcher. The intention was to understand what it is like to live with migraine headache. That which matters most to the participants emerged as the stories unfolded. The researcher maintained full attention to the stories while embracing the real meaning of the experience for each participant. To maintain true presence during the story gathering interview, the researcher walked rhythmically with each participant in a nonjudgmental manner to obtain the story of the phenomena of living with migraine headache. The story served as the foundation for the structure of meaning that emerged in this study.

Connecting with self-in-relation is composed of personal history and reflective awareness, and "is the active process of recognizing self as related with others in a story plot" 
(Smith \& Liehr, 2008, p. 210). Through awakening the story, the narrative of each participant in this study revealed to both the researcher and the participant the true meaning of living with migraine headache from both a historical perspective and the perspective of the present. Further, the future direction of each participant emerged while gathering the story of living with migraine headache. The story gathering process invoked reflective awareness to allow the experiences, feelings and thoughts related to migraine headache to emerge. Reflective awareness led to the unrecognized meaning related to living with migraine headache. Through telling the story to both researcher and to self, the meaning of living with migraine headache may have provided the opportunity to think about their experience in a different way. The findings of this study represented in the structure of meaning explicate the evolving story plot for women living with migraine headache (Smith \& Liehr, 2008).

"Creating ease is an energizing release experienced as the story comes together in movement toward resolving" (Smith \& Liehr, 2008, p. 212). The moments of living with migraine headache were woven together as the researcher maintained a caring presence to allow the stories to surface. Patterns of the participant stories emerged through the interview and data analysis. In the initial data analysis the researcher wrote a reconstructed story for each participant based on the participant descriptions. To anchor the story, the researcher asked the participants to confirm or refute the reconstructed story. Each participant confirmed that the story captured the essence of living with migraine headache. Anchoring the story in this manner may have allowed the participant's to experience calmness, if only for a moment, because the meaning of living with migraine headache was understood by another (Smith \& Liehr, 2008).

Story theory served as a theoretical foundation for gathering the stories of eight women who participated in this study. The researcher maintained true presence with the participants to 
allow the story to unfold. After the stories were reconstructed from the descriptions, each participant confirmed that her story captured the essence of her experiences. This process allowed the participants to experience meaning and moments of ease. One participant confirmed meaning and ease by writing: "You captured my story perfectly. Much better than I could have ever...Thank you for your attention to migraine headaches and getting our stories out there..." The stories obtained by following story theory served as the foundation for the structure of meaning with seven core qualities that emerged during this study.

\section{Significance of the Findings for Nursing}

This study addressed the human health experience of living with migraine headache. Throughout all aspects of the study, the researcher's caring intent to understand the human health experience from the perspective of the woman prevailed. The findings of the study (structure of meaning) explicate core qualities of the human health experience, tie directly to the focus of the discipline, and contribute to the body of knowledge of nursing. This addition to the body of knowledge offers direct guidance for nursing practice.

This study contributes to the body of nursing knowledge a structure of meaning for women living with migraine headache. This structure of meaning captures detail of the lived experience that is not obtained through the standardized tools used to assess the impact of migraine headache. For example, the women in this study reported a lack of true presence at work when "pushing through" in spite of migraine pain. Some standardized tools simply ask about the number of missed work days related to migraine headache. This study revealed the many dimensions of physical and emotional suffering that have not been discussed as a whole in the literature. The outcomes of this study reflect the value of gathering the story of a woman 
living with migraine headache from her perspective. Using story theory, nurses may capture the deeper reality of the migraine experience.

The current nursing literature holds several studies related to living with migraine headache, which warrant discussion in relation to the findings of this study. Peters et al. (2005) found that the pain and associated symptoms of migraine headache as a dominant feature in the descriptions of the migraine experience provided by a total of 13 participants, including two male participants. Additionally, the authors reported that the disabling suffering endured by the participants affected every aspect of their lives.

In contrast, the pain and suffering experienced by participants in this study were delineated within the context of the impact that migraine headache has on all aspects of their lives. This study captured the essence of meaning of living with migraine headache from women and produced a structure of meaning that is based on the rich descriptions of the impact migraine headache has on these women. This structure of meaning illuminates the experience of suffering in the depth and breadth of the human experience.

The structure of meaning that emerged from this study went beyond the concept of migraine triggers to the human experience of living with migraine headache. Although participants in this study mentioned a need to be aware of and try to avoid migraine headache triggers, this was only one aspect of the migraine experience. Their stories of living with migraine headache reflected its profound impact on all aspects of life. In a grounded theory study of 22 women ages 18-61 who experience migraine, the researchers found that the participants were constantly attentive to that which could trigger a migraine headache. Additionally, the participants kept abortive medications close by for ease of access should an attack occur (Meyer, 2002). Distinctively, the description of the lived experience discussed in the current study 
captured the strategizing methods employed by women with migraine headache to obtain medications and keep them close by in an effort to outsmart the attack.

In contrast to the articles noted above that focused on the concept of suffering and migraine triggers, this study contributes to the body of nursing knowledge by providing a rich description of the human health experience of living with migraine headache. The findings address a gap in the literature and capture what other studies have missed. The findings reveal the human lived experience of a reshaped life, vulnerable self, torturous pain, pushing through to hold self together, seeking relief of the torturous pain, getting on with life, and being on guard. These are themes of the experience of living with migraine headache that have not been identified as a whole in the nursing literature. Findings of this study can serve as a foundation for future research related to migraine headache, and inform nursing practice and education.

\section{Implications for Research}

The eagerness with which women volunteered to participate in this study suggests that women who have migraine headache want others to understand what this life experience is like for them. This study highlights the need for replicating this study with women of more diverse backgrounds. Most of the women in this study had college degrees. Participants were either employed, full-time students, or employed and in college. All participants were Caucasian. Studies that ask the same question of women with varying cultural backgrounds, education, and income levels should be developed to instill a better understanding of the challenges faced by all women who suffer from migraines. All of the participants in this study had health insurance; therefore, understanding what it is like to live with migraines for women without health insurance or access to care is another recommendation for future research. The age range for 
participants in this study was 18-62. Research focusing on specific age groups will better inform the literature and nursing practice.

The structure of meaning that emerged from this study indicates that women with migraine headache experience suffering in many forms. A qualitative study focused on the lived experience of suffering for women with migraine headache could be developed. Developing a study using the existential lifeworlds as the framework for gathering descriptive data on the experience of living with migraine headache is warranted. Questions on lived space, lived body, lived time, and lived human relations could be asked about the headache experience. These data could then be analyzed under each of the existential lifeworlds, as well as analyzing how the lifeworlds come together in the headache experience. The core qualities of the lived experience could also be used as a basis for descriptive studies. Story theory as an intervention should be explored. Based on the findings of this study, the researcher intends to design studies that capture the experience of migraine headache from participants living in underserved areas and from those of varied cultural and socioeconomic backgrounds. Story theory will continue to guide these studies while story as an intervention will be studied separately.

\section{Implications for Practice}

The findings in this study have implications for clinical practice. Nurses in various settings may encounter a woman with an active migraine or a history of migraine headache. The structure of meaning which emerged as a result of this study may serve to assist nurses to better understand the experience of living with migraine headache. The core qualities of the structure of meaning could be used in the assessment of a woman's migraine experience. For example, asking a woman with migraine headache about what it is like for her at work at home or in social settings will enable the nurse to better understand the unique experience of a woman with 
migraine headache and design caring interventions that address the complicating health challenge from her perspective. Nurses could use story theory as a framework to facilitate the telling of what matters most to the woman that day as she presents her health challenge. As the nurse facilitates a process of giving voice to those suffering, healing has the opportunity to take place.

Women with migraine headache endure many forms of suffering. Nurses have the opportunity to facilitate the sharing of the suffering experience through the intentional dialogue of story. This process of recognizing and addressing the suffering endured by women with migraine could be based on story theory and may be used by nurses in any setting (Smith \& Liehr, 2008).

\section{Implications for Education}

This study suggests that there is a need to educate nurses about the importance of listening to a patient's story. Student nurses could be taught the premise behind story theory during the first year. The theory could then be threaded throughout the curriculum to include each semester of the program. Opportunities exist for students to practice gathering the stories in the clinical setting. Additionally, student experiences during simulation could allow this education to develop through a scenario of story gathering with the opportunity for formal feedback.

Nursing education also needs to address the experience of suffering. As novice nurses complete formal education and enter the work force, a significant amount of knowledge regarding the suffering women endure with migraine would provide a foundation for a story centered approach to nursing care. Nurses could benefit from having instruction on what constitutes suffering. A discussion in the classroom that explicates the premise of suffering and 
story theory could serve as a solid building block that students would then be able to apply in the clinical setting.

This study may serve as a guide for understanding the full impact of migraine headache on a woman's life. The appreciation of this impact from a holistic viewpoint could serve to educate practicing nurses who care for women with migraine headache. Education designed to assist practicing nurses in understanding how to ascertain the story of women suffering with migraine in a timely manner is warranted. These nurses could benefit from interactive teaching that assists them in learning to incorporate intentional dialogue in interactions with patients.

\section{Summary}

This study revealed a structure of meaning, comprised of seven interrelated core qualities, for women living with migraine headache. Living with migraine headache is: (a) recalling the significant experience that reshaped life; (b) experiencing self as vulnerable, with unmet expectations, unfulfilled relationships, and regrets; (c) being overcome by unrelenting, torturous pain magnified by intrusion from the outside world; (d) pushing through to hold self together to do what needs to be done, in spite of torturous pain; (e) surrendering to the compelling call to focus on self in order to relieve the torturous pain; (f) making the most of pain-free time to get on with life and navigating the aftermath of the headache experience; and ( $\mathrm{g}$ ) being on guard against an unpredictable attack and yet hopeful that it is possible to outsmart the next attack.

This understanding of the lived experience of women with migraine headache emerged by carefully following methods suggested by van Manen (1997) and story theory (Smith \& Liehr, 2008). This study informs both theories because it captured the story of women living with migraine from an existential lifeworld perspective. The findings address a gap in the literature and capture the depth and breadth of the human experience of living with migraine that 
other studies have missed. The findings reveal the human lived experience of a reshaped life, vulnerable self, torturous pain, pushing through to hold self together, seeking relief of the torturous pain, getting on with life, and being on guard. These are themes of the experience of living with migraine headache that have not been identified as a whole in the nursing literature. Findings of this study can serve as a foundation for future research related to migraine headache, and inform nursing practice and education. 


\section{References}

Alvarez, W. C. (1963, January). Notes on the history of migraine. Headache, 2(4), 209-213. doi: 10.1111/j.1526-4610.1963.hed0204209.

Belam, J., Harris, G., Kernick, D., Kline, F., Lindley, K., McWatt, J., Mitchell, A., \& Reinhold, D. (2005, February). A qualitative study of migraine involving patient researchers. British Journal of General Practice, 55(511), 87-93. Retrieved from http://www.ncbi.nlm.nih.gov/pmc/articles/PMC1463213/

Berry, P. A. (2007, February). Migraine disorder: Workplace implications and solutions. AAOHN Journal, 55(2), 51-56. Retrieved from http://www.aaohnjournal.com/showAbst.asp?thing=34136

Birtch, F. W. (1910, August). Report of a case of sick-headache. California State Journal of Medicine, VIII(8), 281-282. Retrieved from http://www.ncbi.nlm.nih.gov/pmc/articles/PMC1893397/

Brandes, J. L. (2006, April 19). The influence of estrogen on migraine: A systematic review. Journal of the American Medical Association, 295(15), 1824-1830. Retrieved from http://jama.ama-assn.org/cgi/content/abstract/295/15/1824

Cohen, M. Z. (2000a). Ethical Issues and Ethical Approval. In Hermenuetic Phenomenological Research: A practical guide for nurse researchers (pp. 37-44). Thousand Oaks, CA: Sage.

Cohen, M. Z. (2000b). Introduction. In Hermenutic Phenomenological Research: A practical guide for nurse researchers (pp. 1-12). Thousand Oaks, CA: Sage. 
Cole, J. C., Lin, P., \& Rupnow, M. F. (2007, September). Validation of the Migraine-Specific Quality of Life Questionnaire version 2.1 (MSQ v. 2.1) for patients undergoing prophylactic migraine treatment. Quality of Life Research, 16(7), 1231-1237. Retrieved from http://www.ncbi.nlm.nih.gov/pubmed/17468941

Dowling, M. (2007). From Husserl to van Manen. A review of different phenomenological approaches. International Journal of Nursing Studies, 44(1), 131-142. doi: 10.1016/j.ijnurstu.2005.11.026

Durham, C. F., Alden, K. R., Dalton, J., Carlson, J., Miller, D. W., Englebardt, S. P., \& Neelon, V. J. (1998, June ). Quality of life and productivity in nurses reporting migraine. Headache, 38, 427-435. doi: 10.1046/j.1526-4610.1998.3806427.x

Elston-Lafata, J., Moon, C., Leotta, C., Kolodner, K., Poisson, L., \& Lipton, R. B. (2004). The medical care utilization and costs associated with migraine headache. Journal of General Internal Medicine, 1005-1012. doi: 10.1111/j.1525-1497.2004.30021.x.

Ferrell, B. R., \& Coyle, N. (2008). The nature of suffering and the goals of nursing. New York, NY: Oxford University Press.

Flaming, D. (1995). Patient suffering: A taxonomy from the nurse's perspective. Journal of Advanced Nursing, 22(6), 1120-1127. doi: 10.1111/j.1365-2648.1995.tb03113.x 
Gallagher, R. M., Mueller, L., Steer, R., \& Ciervo, C. A. (1998). Myers-Briggs personality type classification of migrainous women. Headache Quarterly, Current Treatment and Research, 9(2), 149-152. Retrieved from http://www.library.nhs.uk/booksandjournals/details.aspx?t=myersbriggs+personality+migrainous+women $\& s t f o=$ True\&sc=bnj.ovi.amed,bnj.ovi.bnia,bnj.eb s.cinahl,bnj.ovi.emez,bnj.ebs.heh,bnj.ovi.hmic,bnj.pub.MED,bnj.ovi.psyh\&p=1\&sf=srt.p ublicationdate $\&$ sfld=fld .any \&sr=bnj.ebs\&did=1998053395\&pc=1\&id=5

Hormonal status determines the treatment of hormone-related headache in women. (2007). Drugs \& Therapy Perspectives, 23(1), 14-17. Retrieved from http://direct.bl.uk/bld/PlaceOrder.do?UIN=200673109\&ETOC=RN\&from=searchengine

Kahn, D. L., \& Steeves, R. H. (1986). The experience of suffering: Conceptual clarification and theoretical definition. Journal of Advanced Nursing, 11(6), 623-631. doi: 10.1111/j.13652648.1986.tb03379.x

Kolotylo, C. J., \& Broome, M. E. (2000a, December). Predicting disability and quality of life in a community-based sample of women with migraine headache. Pain Management Nursing, 1(4), 139-151. doi: 10.1053/jpmn.2000.19344

Kolotylo, C. J., \& Broome, M. E. (2000b). Exploration of migraine pain, disability, depressive symptomatology, and coping: A pilot study. Health Care for Women International, (3), 203-218. doi: 10.1080/073993300245267 Retrieved from

Kwong, W. J., \& Pathak, D. S. (2007, April). Validation of the eleven-point pain scale in the measurement of migraine headache pain. Cephalalgia, 27(4), 336-342. doi: 10.1111/j.1468-2982.2007.01283.x 
Lipton, R. B., Stewart, W. F., Diamond, S., Reed, M. L., \& Reed, M. (2001). Prevalence and burden of migraine in the United States: Data from the American Migraine Study II. Headache, 41(7), 646-657.

LoBiondo-Wood, G., \& Haber, J. (1998). Nursing reseach: Methods, critical appraisal, and utilization (4th ed.). St. Louis, MO: Mosby.

Magiorkinis, E., Diamantis, A., Mitsikostas, D., \& Androutsos, G. (2009). Headaches in antiquity and during the early scientific era. Journal of Neurology, 256(8), 1215-1220. doi: $10.1007 / \mathrm{s} 00415-009-5085-7$

Mannix, L. K. (2008). Menstrual-related pain conditions: Dysmenorrhea and migraine. Journal of Women's Health, 17(5), 879-891. doi: 10.1098/jwh.2007.0440

Marcus, D. A., Kapelewski, C., Jacob, R. G., Rudy, T. E., \& Furman, J. M. (2004, April). Validation of a brief nurse-administered migraine assessment tool. Headache, 44(4), 328-332. Retrieved from http://www.ncbi.nlm.nih.gov/pubmed/15109357

Martin, B. C., Pathak, D. S., Sharfman, M. I., Adelman, J. U., Taylor, F., \& Kwong, W. J. (2000, March). Validity and reliability of the Migraine-Specific Quality of Life Questionnaire (MSQ version 2.1). Headache, 40(3), 204-215. Retrieved from http://www.ncbi.nlm.nih.gov/pubmed/10759923

Meyer, G. A. (2002, November). The art of watching out: Vigilance in women who have migraine headache. Qualitative Health Research, 12(9), 1220-1234. doi: $10.1177 / 1049732302238246$

Moffitt, H. C. (1911, September). Clinical observations on migraine. California State Journal of Medicine, 9(9), 358-361. Retrieved from http://www.ncbi.nlm.nih.gov/pmc/articles/PMC1893999/ 
Moloney, M. F., Strickland, O. L., DeRossett, S. E., Melby, M. K., \& Dietrich, A. S. (2006, Third Quarter). The experiences of midlife women with migraines. Journal of Nursing Scholarship, (3), 278-285. doi: 10.1111/j.1547-5069.2006.00114.x

Mongini, F., Fassino, S., Rota, E., Deregibus, A., Levi, M., Monticone, D., \& Abbate-Daga, G. (2005). The temperament and character inventory in women with migraine. Journal of Headache and Pain, 6(4), 247-249. doi: 10.1007/s10194-005-0198-6

Moran, D. (2000). Introduction to phenomenology. New York, NY: Routledge.

Morse, J. M. (2001, September). Toward a praxis theory of suffering. Advances in Nursing Science, 24(1), 47-59. Retrieved from http://www.ncbi.nlm.nih.gov/pubmed/11554533

Nappi, G., Jensen, R., Nappi, R. E., Sances, G., Torelli, P., \& Olesen, J. (2006). Diaries and calendars for migraine: A review. Cephalalgia, 26(8), 905-916. doi: 10.1111/j.14682982.2006.01155.x

Newman, M. A., Sime, A. M., \& Corcoran-Perry, S. A. (1991, September). The focus of the discipline of nursing. Advances in Nursing Science, 14(1), 1-6.

Peters, M., Abu-Saad, H. H., Vydelingum, V., Dowson, A., \& Murphy, M. (2004). Migraine and chronic daily headache management: A qualitative study of patients' perceptions. Scandinavian Journal of Caring Sciences, 18(3), 294-303. doi: 10.1111/j.14716712.2004.00279.x

Peters, M., Abu-Saad, H. H., Vydelingum, V., Dowson, A., \& Murphy, M. (2005, February). The patients' perceptions of migraine and chronic daily headache: A qualitative study. The Journal of Headache and Pain, 6(1), 40-47. doi: 10.1007/s 10194-005-0144-7

Polit, D. F., \& Hungler, B. P. (1997). Essentials of nursing research: Methods, appraisal, and utilization (4th ed.). Philadelphia, PA: Lippincott. 
Reed, P. G. (1995, March). A treatise on nursing knowledge development for the 21st century: Beyond postmodernism. Advances in Nursing Science, 70-84. Retrieved from http://www.ncbi.nlm.nih.gov/pubmed/7778892

Riley, H. A. (1932, December). Migraine and its treatment. Bulletin of the New York Academy of Medicine, 8(12), 717-746. Retrieved from http://www.ncbi.nlm.nih.gov/pmc/articles/PMC2096318/

Ruiz de Velasco, I., Gonzalez, N., Etxeberria, Y., \& Garcia-Monco, J. C. (2003). Quality of life in migraine patients: A qualitative study. Cephalalgia, 23, 892-900. doi: 10.1046/j.1468-2982.2003.00599.x

Sandelowski, M. (1986). The problem of rigor in qualitative research. Advances in Nursing Science. doi: 10.1177/104973230201200211

Silberstein, S. D., Lipton, R. B., \& Dodick, D. W. (Eds.). (2008). Wolff's headache and other head pain (8th ed.). Oxford, NY: Oxford University Press.

Smith, M. J., \& Liehr, P. R. (Eds.). (2008). Middle range theory for nursing (2nd ed.). New York, NY: Springer.

Smith, T., Blumenthal, H., Diamond, M., Mauskop, A., Ames, M., McDonald, S., Lener, S., \& Burch, S. (2007). Sumatriptan/naproxen sodium for migraine: Efficacy, health related quality of life, and satisfaction outcomes. Headache, 47(5), 683-692. doi: 10.1111/j.1526-4610.2007.00790.x

Solomon, S. (2007). Major therapeutic advances in the past 25 years. Headache, 47(Suppl 1), S20-S22. doi: 10.1111/j.1526-4610.2007.00673.x 
Stewart, W. F., Lipton, R. B., Kolodner, K. B., Sawyer, J., Lee, C., \& Liberman, J. N. (2000). Validity of the Migraine Disability Assessment (MIDAS) Score in comparison to a diarybased measure in a population sample of migraine sufferers. Pain, 88(1), 41-52. Retrieved from http://linkinghub.elsevier.com/retrieve/pii/S0304395900003055

Stewart, W. F., Lipton, R. B., Kolodner, K., Liberman, J., \& Sawyer, J. (1999). Reliability of the migraine disability assessment score in a population-based sample of migraine sufferers. Cephalalgia, 19, 107-114. Retrieved from http://cep.sagepub.com/content/vol19/issue2/\#ORIGINAL_ARTICLES

Stewart, W. F., Lipton, R. B., Dowson, A. J., \& Sawyer, J. (2001). Development and testing of the Migraine Disability Assessment (MIDAS) Questionnaire to assess headache-related disability. Neurology. doi: 10.1007/s10072-004-0302-8

Van Manen, M. (1990). Researching lived experience: Human science for an action sensitive pedagogy (1st ed.). New York, NY: State University of New York Press.

Van Manen, M. (1997). Researching lived experience: Human science for an action sensitive pedagogy (2nd ed.). Ontario, Canada: The Althouse Press.

Vick, R. M., \& Sexton-Radek, K. (2005). Art and migraine: Researching the relationship between artmaking and pain experience. Art Therapy: Journal of the American Art Therapy Association, 26(3), 114-123. Retrieved from http://www.eric.ed.gov/ERICWebPortal/custom/portlets/recordDetails/detailmini.jsp?_nf pb=true\&_\&ERICExtSearch_SearchValue_0=EJ722382\&ERICExtSearch_SearchType_ $0=$ no\&accno $=\mathrm{EJ} 722382$ 
Vujevich, K. (2007, September). What makes women's migraines different. The Clinical Advisor, 33-38. Retrieved from http://www.clinicaladvisor.com/what-makes-womensmigraines-different/article/117416/

Weitzel, K. W., Strickland, J. M., Smith, K. M., \& Goode, J. R. (2001). Gender-specific issues in the treatment of migraine. Journal of Gender-Specific Medicine, 4(1), 64-74. Retrieved from http://www.ncbi.nlm.nih.gov/pubmed/11324243

Wikberg, A., Jansson, L., \& Lithner, F. (2000). Women's experience of suffering repeated severe attacks of acute intermittant porphyria. Journal of Advanced Nursing, 1348-1355. doi: 0.1046/j.1365-2648.2000.01628.x

Wright, W. (2008, June). The functional and Emotional Effects of Migraine. Advance for Nurse Practitioners, 16(6), 43-46.

Ziegler, D. K., Hurwitz, A., Hassanein, R. S., Kidanaz, H. A., Preskorn, S. H., \& Mason, J. (1987, May). Migraine prophylaxis: A comparison of propanolol and amitriptyline. Archives of Neurology, 44(5), 486-489. Retrieved from http://archneur.amaassn.org/content/vol44/issue5/index.dtl 
Appendix A

\section{WWestVurginiaUniversity. \\ Office of Research Compliance}

The research study referenced above was reviewed by the West Virginia University Instituional Review Board (IRB) via expedited review procedures and was approved in accordance with 46 CFR 46.101(b).

This protocol was reviewed using the following:

Initial Expedited Review Checklist (210a)

Informed Consent - Only Minimal Risk Checklist (210z)

Advertisement Checklist (210i)

category 7

Locations of Research

Offsite Location Details

Attachments - Other (e.g., community hospital, nursing home, long-term care facility, private residence, etc.)

Ramsey facility use.pdf Permission to Use Radford University Facilities Letter from RU School of Nursing Director

Surveys, Questionnaires, Interviews

Attachments

The following documents have been approved and validated for use in this study and are available in the BRAAN system:

To: Burkhardt, Margaret

From: WVU Office of Research Compliance

Date: Friday, September 17, 2010

Subject: Approval Letter

Tracking \#: $\mathrm{H}-22664$

Title: Living with migraine headache: A phenomenological study of women's experiences

\section{Expedited-IRB Protocol-Approval}

Board Designee: White, Barbara

Thank you.

Attachments

Living with migraine headache - interview question 2.doc rationale for not using a survey or questionnaire

Ramsey demographic info form 9-3-10.pdf Demographic information sheet

Consent Form(s)

Forms

Living with Migraine Headache

Miscellaneous Attachments

Attachments

CITI Collaborative Institutional Training Initiative.pdf Ramsey CITI Training

citti training completion report.doc CITI training verification for Dr. Margaret A. 
(Peggy) Burkhardt

Ramsey advertisement 9-3-10.pdf Recruitment advertisement Study Contacts for Medical or Emotional Assistance.pdf Emergency Contacts Once you begin your human subject research, the following regulations apply: 1. Unanticipated or serious adverse events/side effects encountered in this research study must be reported to the IRB within five (5) days.

2. Any modifications to the study protocol or informed consent form must be reviewed and approved by the IRB prior to implementation.

3. You may not use a modified informed consent form until it has been approved and validated by the IRB.

Letter Sent By: White, Barbara, 9/17/2010 1:49 PM 


\title{
Appendix B
}

\author{
Radford University's Institutional Review Board \\ Office of Sponsored Programs and Grants Management \\ P.O Box 6926 Radford, VA 24142 / Phone: (540) 831-5290 / Fax: (540) 831-6636 / irb-iacuc@radford.edu
}

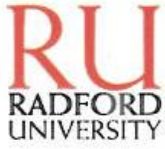

October 4, 2010

TO:

Anthony Ramsey, MSN, FNP-C

FROM:

Laura Noll (Inoll@radford.edu)
Radford University IRB

RE:

Approval for FY11-016: Living with migraine headaches: A phenomenological study of women's experiences

STUDY TITLE:

[192803-1] Living with migraine headaches: A phenomenological study of

IRB REFERENCE \#: women's experiences

SUBMISSION TYPE:

FY11-016

New Project

ACTION:

APPROVED

EFFECTIVE DATE:

EXPIRATION DATE:

REVIEW TYPE:

October 4, 2010

October 3, 2011

Expedited Review

REVIEW CATEGORY:

This is to confirm that the above-referenced study submitted for Expedited Review to Radford University's Institutional Review Board (IRB) has been granted approval.

Your IRB-sanctioned approval ends on October 3, 2011, by which date a closure report is due. If you wish to continue your research beyond this date, you must request a continuance no later than 10 days prior to the expiration of this approval. Because your study requires documentation of informed consent, you must use the stamped copy of your approved consent document.

If your protocol should change, please submit a request for modification. IRB forms can be accessed from your Forms and Templates library in IRBNet.

As the principal investigator for this project, you are ultimately responsible for ensuring that your study is conducted in an ethical manner. You are also responsible for filing all reports related to this project.

If you have any questions, please contact Laura Noll at (540) 831-5290 or Inoll@radford.edu. Please include your study title and reference number in all correspondence with this office.

Good luck with this project! 
Appendix $C$

\section{A Study of Women Living with Migraine headache Volunteers Wanted for a Research Study}

Anthony Ramsey, RN, FNP-C, a Radford University Nursing Faculty Member and a Nursing PHD student at West Virginia University is seeking volunteers to take part in a research study focused on what it is like for women to live with migraine headache. Mr. Ramsey will conduct an interview with each volunteer that will last about one hour. This research will help nurses to learn more about what it is like for women to have migraine headache so that they can give better care to these women.

Eligibility: Women over the age of 18 who have been diagnosed with migraine headache by a healthcare provider.

To Participate: Contact Anthony Ramsey, RN, FNP-C at 540-449-1616 or e-mail at arramsey@radford.edu 


\section{Appendix D}

\section{Dear Participant,}

This letter is a request for you to take part in a research project to understand what it is like to live with migraine headache. This project is being conducted by Dr. Margaret Burkhardt, a West Virginia University Professor of Nursing with supervision of Anthony R. Ramsey, a West Virginia University PhD in nursing student. Your participation in this project is greatly appreciated and will take approximately 1 hour to complete the interview.

Your involvement in this project will be kept as confidential as legally possible. All data will be reported in the aggregate. You must be 18 years of age or older to participate. I will not ask any information that should lead back to your identity as a participant. Your participation is completely voluntary. You may skip any question that you do not wish to answer and you may discontinue at any time. West Virginia University's Institutional Review Board acknowledgement of this project is on file.

I hope that you will participate in this research project, as it could be beneficial in understanding the impact of migraine headache on women. Thank you very much for your time. Should you have any questions about this letter or the research project, please feel free to contact Anthony Ramsey at (540) 449-1616 or by e-mail at arramsey@radford.edu.

Thank you for your time and help with this project.

Sincerely,

Anthony R Ramsey 


\section{Appendix E}

\section{Local Contacts for Medical or Emotional Assistance}

Carilion New River Valley Medical Center is located with three miles of the university, and offers emergency medical as well as acute and chronic mental health services. Location: 2900 Lamb Circle, Christiansburg, Va. 24141

Phone: $540-731-2000$

Valley Counseling Services is located one block from Radford University, and offers continuing counseling to the general public.

Location: 600 East Main Street, Radford, VA. 24141

Blue Ridge Counseling Services is located within two miles of Radford University and offers continuing counseling services.

Location: 519 Second Street, Radford, VA. 24141

Phone: 540-639-9040 
Appendix $F$

\section{W. WestVirginiaUniversity.}

Office of Research Compliance

CONSENT AND INFORMATION FORM

Living with Migraine Headache

Principal Investigator:

Department:

Tracking Number:

Contact Persons

In the event you experience any side effects or injury related to this research, you should contact Dr. Burkhardt at 304-347-1253 or Mr.

Ramsey at 540-449-1616

If you have any questions, concerns, or complaints about this research, you can contact Dr. Burkhardt at 304-347-1253 or Mr. Ramsey at 540-449 $-1616$

Introduction

In addition if you would like to discuss problems, concerns, have suggestions related to research, or would like to offer input about the research, contact the Office of Research Integrity and Compliance at 304293-7073.

Burkhardt, Margaret

NURSING

$\mathrm{H}-22664$

Sponsor

None

For information regarding your rights as a research subject, you may contact the Office of Research Compliance at 304/293-7073.

Study Title:

Co-Investigator(s):

Ramsey, Anthony

Living with migraine headache: A phenomenological study of women's experiences

Initials Date

Page 16

Approved On:

Valid Through:

Last Amended:

$\mathrm{H}-22664$

$\mathrm{N} / \mathrm{A}$

$09 / 17 / 2010$

09/16/2011

Tracking \#: of

$\mathrm{H}-22664$

You, have been asked to participate in this research study, which has been explained to you by Anthony Ramsey, RN, 
FNP-C. This study is being conducted by Dr. Margaret Burkhardt and Mr. Anthony Ramsey in the School of Nursing at West Virginia University. This research is being conducted to fulfill the requirements for a doctoral dissertation in Nursing in the School of Nursing at West Virginia University, under the supervision of Margaret Burkhardt, PhD, RN.

\section{Purposes of the Study}

\section{Description of Procedures}

This study involves an audio recorded interview and will take approximately one hour for you to complete. After the interview you will be asked to answer a few questions regarding your age, education level, relationship status, pregnancy history, profession and health insurance status. If you wish to do so, you may see a list of all questions before you agree to participate in this study. Answering these questions will take approximately 5 minutes. You do not have to answer all of the questions. You will be provided a copy of medical referrals should you experience physical or emotional distress related to the interview.

\section{Risks and Discomforts}

The only potential risks for participants associated with the study are mild frustration associated with answering questions and the potential for emotional distress that may result from discussing a chronic health condition such as migraine headache.

The purpose of this study is to learn more about what it is like to live with migraine headache. WVU expects 15 subjects to be recruited in Virginia.

\section{Alternatives}

Alternatives that could be considered in your case include not participating in this study.

You do not have to participate in this study.

Initials Date

Page 26

Approved On:

Valid Through:

Last Amended:

$\mathrm{H}-22664$

$\mathrm{N} / \mathrm{A}$

$09 / 17 / 2010$

09/16/2011

Tracking \#: of

Tracking \#: H-22664

\section{Benefits}

You may not receive any direct benefit from this study. The knowledge gained from this study may eventually benefit others.

Any information about you that is obtained as a result of your participation in this research will be kept as confidential as legally possible. Your research records, just like hospital records, may be subpoenaed by court order or may be inspected by federal regulatory authorities without your additional consent. Audiotapes will be kept locked up and will be destroyed as soon as possible after the research is finished. In any publications that 
result from this research, neither your name nor any information from which you might be identified will be published without your consent. We know that information about you and your health is private. We are dedicated to protecting the privacy of that information. Because of this promise, we must get your written authorization (permission) before we may use or disclose your protected health information or share it with others for research purposes.

You can decide to sign or not to sign this authorization section. However, if you choose not to sign this authorization, you will not be able to take part in the research study. Whatever choice you make about this research study, it will not have an effect on your access to medical care. Persons/Organizations receiving the information: The members and staff of any Institutional Review Board (IRB) that oversees this research study.

- West Virginia University Office of Research Compliance and Office of Sponsored Programs.

The following information will be used: the participant's age, age at migraine diagnosis, education level, place of healthcare for migraines, heath insurance status, marriage/ domestic relationship status, pregnancy history, and what they do for a living. Each participant will be assigned a

Confidentiality

There are no special fees for participating in this study.

\section{Financial Considerations}

Initials Date

Page 36

Approved On:

Valid Through:

Last Amended:

$\mathrm{H}-22664$

$\mathrm{N} / \mathrm{A}$

09/17/2010

09/16/2011

Tracking \#: of

Each participant will be assigned a pseudonym and number to protect personal health information

The information is being disclosed for the following reasons: •

Publication of study results (without identifying you)

You may cancel this authorization at any time by writing to the

Principal Investigator:Dr. Margaret Burkhardt West Virginia

University School of Nursing $\mathbf{3 1 1 0}$ MacCorkle Ave. SE Charleston, WV 25304

If you cancel this authorization, any information that was collected already for this study cannot be withdrawn. Once information is disclosed, according to this authorization the recipient may redisclose it and then the information may no longer be protected by federal privacy regulations. This authorization will not expire unless you cancel it. (or has a specific expiration date) 


\section{SIGNATURE}

I have read this section and all of my questions have been answered. By signing below, I acknowledge that I have read and accept all of the above.

Signature of Subject or Authorized Representative Date

Print Name of Subject or Authorized Representative

Participation in this study is voluntary. You are free to withdraw your consent to participate in this study at any time. Refusal to participate or withdrawal will not affect your future care, [or your employee status at Radford University or your class standing or grades, as appropriate] and will involve no penalty to you. In the event new information becomes available that may affect your willingness to participate in this study, this Voluntary Participation

Initials Date

Page 46

Approved On:

Valid Through:

Last Amended:

$\mathrm{H}-22664$

$\mathrm{N} / \mathrm{A}$

$09 / 17 / 2010$

09/16/2011

Tracking \#: of

This information will be given to you so that you can make an informed decision about whether or not to continue your participation. You have been given the opportunity to ask questions about the research, and you have received answers concerning areas you did not understand.

Initials Date

Page 56

Approved On:

Valid Through:

Last Amended:

$\mathrm{H}-22664$

$\mathrm{N} / \mathrm{A}$

$09 / 17 / 2010$

$09 / 16 / 2011$

Tracking \#: of

Tracking \#: H-22664

I willingly consent to participate in this research.

Signature of Investigator or Printed Name Date Time

Co-Investigator

The participant has had the opportunity to have questions addressed. The participant willingly agrees to be in the study.

Upon signing this form, you will receive a copy.

Signature of Subject or Printed Name Date Time

Subjects Legal Representative

Initials Date

Page 66

Approved On:

Valid Through:

Last Amended:

$\mathrm{H}-22664$

$\mathrm{N} / \mathrm{A}$ 
Appendix $G$

\author{
HIPAA1 AUTHORIZATION TO USE AND DISCLOSE \\ INDIVIDUAL HEALTH INFORMATION FOR RESEARCH PURPOSES \\ 1 HIPAA is the Health Insurance Portability and Accountability Act of 1996, a federal law related to privacy of \\ health information.
}

\title{
Principal Investigator: Margaret Burkhardt, PhD
}

\section{Title of the Study: Living with migraine headache: A phenomenological study of women's experiences}

This form relates to the study above. It tells what information about you that may be collected in this study and who might see or use it.

You have been given another Consent Form to participate in the study.

Radford University has rules to protect information about you. Federal and state laws also protect your privacy.

Generally, only people working on the research team will know that you are in research study and will see your information. However, there are a few exceptions such as the ones that are listed later in this form.

1. Authorization. As a research participant, you authorize Margaret Burkhardt, $\mathrm{PhD}, \mathrm{RN}$ to use and disclose your individual health information for the purpose of conducting the research project entitled: Living with migraine headache: A phenomenological study of women's experiences

2. Information to Be Used or Disclosed. Your individual health information that may be used or disclosed to conduct the study includes: your age, age at migraine diagnosis, education level, place of healthcare for migraines, health insurance status, marriage/domestic relationship status, pregnancy history, and what you do for a living.

3. Parties Authorized to Disclose Information. The researcher may obtain your individual health information from you in verbal and written form.

4. Parties Who May Receive or Use Information. Your individual health information disclosed by parties listed in item 3 and information disclosed by you or discovered about you during the course of the research may be received and used by Margaret Burkhardt, PhD, RN, and study co-investigator Anthony Ramsey, MSN, FNP-C.

5. Right to Refuse to Sign this Authorization. You understand that you do not have to sign this Authorization. If you do not sign, then you will not be allowed to participate in the study or receive any treatment that may be provided through the study. However, your decision not to sign this Authorization will not affect any other treatment, payment, or enrollment in health plans or eligibility for benefits.

6. Right to Withdraw Authorization. You understand you can change your mind and withdraw this Authorization at any time by sending a written notice to Anthony Ramsey, MSN, FNP-C to inform the researcher of your decision. If you withdraw this Authorization, the researcher may only use and disclose individual health information already collected for the study. No additional health information about you will be collected by or disclosed to the researcher for the study.

7. Potential Re-disclosure. Your individual health information disclosed under this Authorization may be subject to re-disclosure outside the research study and no longer be protected under certain circumstances such as mandated reporting of abuse or neglect, required disclosures for law enforcement purposes, and for health oversight activities and public health purposes. 
8. Suspension of Access to Health Records. You understand that you may not be allowed to review information collected about you for this study, including information recorded in your medical record, until the study is completed. When the study is over, you will have the same rights to access the information as you had before enrolling in the study.

9. Expiration of Authorization. This authorization will expire upon completion of the study.

I am the research participant or the personal representative authorized to act on behalf of the participant. I have read this information, and I understand I will receive a copy of this Authorization when it has been signed.

Name of Subject (type or print)

Signature

Date

Name of Legal Representative ${ }^{2}$

(Legal guardian, authorized surrogate under Uniform Health Care Decisions Act)

Describe authority of personal representative to act on behalf of the research subject:

Signature of Subject or Legal Representative

Printed Name and Signature of Person Obtaining Consent
Date

Date

\footnotetext{
${ }^{2}$ Persons from the following categories in order of priority may be a Legally Authorized Representative: (1) the parent or parents having custody of a prospective subject who is a minor, (2) the agent appointed under an advance directive, provided the advance directive authorizes the agent to make decisions regarding the prospective subject's participation in human research, (3) the legal guardian of a prospective subjective, (4) the spouse of the prospective subject, except where a suit for divorce has been filed and the divorce decree is not yet final, (5) an adult child of the prospective subject, (6) a parent of the prospective subject when the subject is an adult, (7) an adult brother or sister of the prospective subject, or (8) any person or judicial or other body authorized by law or regulation to consent on behalf of a prospective subject to such subject's participation in the particular human research
} 


\section{Appendix $H$}

\section{Living with migraine headache: A phenomenological study of women's experiences}

\section{Demographic Information}

Please provide the answers to the following questions:

1. How old are you? years

2. How old were you when your health care provider said that you had migraine headaches? years

3. I am currently: (Circle One)
a. Single
b. Married (or living with a partner)
c. Divorced or Separated
d. Widowed

4. Do you have health insurance? (Yes/No)

5. Where do you currently receive healthcare for your migraines? (Circle One)
a. Primary Healthcare Provider
b. Free Clinic
c. Emergency Room
d. Student Health
e. Other

6. Have you ever been pregnant? (Yes/No)

7. How far did you go in school? (Circle One)
a. Middle School
b. Some High School
c. High School Diploma
d. Some College
e. College Degree
f. Graduate Degree

8. What do you do for a living? 


\section{Appendix I \\ The Story of "Mary" \\ Participant 1 \\ Anthony Ramsey \\ Revised January 12, 2011}

Mary is a thirty-three year old woman with two children. A single mother with a history of migraine headache since age 16, Mary holds two part-time jobs and is a full-time nursing student. Mary states that she is a "perfectionist" who tries very hard to complete her work as best as she knows how and in a timely manner.

As a teenager, Mary would retreat to her self-described cocoon that consisted of her bed, covers over her head, and complete silence. The cocoon created an environment where Mary did not have to focus on anything. The environment created a sense of ease, as did the presence of her mother who knew exactly what to do because she too suffers from migraines. Wallowing in her cocoon, not interacting with others and being alone brought Mary the relief no medication could provide.

Today, Mary's children create the need for cocooning with one eye open so that she can be sure that they are safe and that their needs are met. She has to focus and listen for signs that her children need her attention or assistance. Mary feels guilty because her headaches keep her from being the perfect Mom who attends every soccer game and cheers loudly. She can't go to the games with a headache because the bright sunlight and loud voices drive her to her now modified cocoon.

Mary can predict a migraine that accompanies her menstrual period, and expects to mend fences after the migraine subsides. She can play with her children, or vacuum the floors again to capture the detail she embraces. However, the most troublesome headaches are those she cannot anticipate. These headaches have the potential to cause Mary to miss an event or obligation, causing her anxiety and disappointment. Mary worries about projecting negativity upon others and prefers to always be bright and chipper. She feels as if her puffy eyes that accompany a headache will invoke the sympathy from others she does not want. All she wants is to push through the day and retreat to her safe place at home. She states that she is too busy to stop for migraines or to think about migraines. She wants her life to proceed as if she did not have migraine headache. She wants others, especially her children, to see her as someone who does not have migraines.

Mary does all she can to prevent migraines. She exercises, avoids caffeine and foods which are migraine triggers for her, and she tries to make time for relaxation. She feels as if healthcare providers find her to be a "tired and whiny" woman. Navigating the healthcare system is difficult because she cannot see her doctor when the headache occurs. Migraine is considered a chronic illness, so when she calls with a sick headache she is given an appointment for the next month. She takes very little medication because few offer relief. She is resolved to waiting out each headache. 


\section{The Story of "Elizabeth" \\ Participant 2 \\ Anthony Ramsey \\ Revised January 12, 2011}

Elizabeth was diagnosed with migraines by a pediatrician at age three. She was told that when her headaches began at such a young age, the only outward symptoms were uncontrollable crying and vomiting. Although she doesn't remember headaches that early in her life, she remembers headaches affecting her life at age five and beyond. She also remembers that it was anxiety that triggered her migraines. She never wanted stress or trouble at any point in her life. Elizabeth does feel like that she missed out on some important childhood events due to her headaches that were possibly a result of unexpected anxiety. However, she does not view headaches as a disability. Instead, she considers migraine as something that has always been there. She accepts the headaches as part of who she is as a woman.

At age 13, Elizabeth started carrying her medications in her purse and did not rely on the school nurse to dispense them. She acknowledges that she broke the school rules by self-administering, but doing so allowed her the freedom to treat herself immediately, and without the pity that may accompany seeing the school nurse. As a teenager, Elizabeth also learned to manage the migraine triggers of anxiety, a cold environment, and lack of sleep. This was accomplished through supportive and "laid back" parents. On the other hand, the missed sleepovers, birthday parties and football games created a void in Elizabeth's childhood.

Now twenty years old, Elizabeth is a college student who experiences all of the stressors of college life. She considers her medications and her mother to be her best headache treatments, yet the medications cause sleepless nights with the risk for another headache, and her mother is not with her at the university. Elizabeth's first college roommate did not have the experience of helping her through a migraine. She missed her mother who lets her be, but yet knows when to speak. Her significant other of seven years has become a strong support, much like Mom. Other people in Elizabeth's life are learning what she needs during a migraine. They are slowly realizing that she can't drive, focus her mind, or go out for an evening of fun. The new people in Elizabeth's life try their best to help.

Elizabeth works to prevent the migraines. She tries not to let herself become anxious, but the stresses of college such as the first day of school or a big test overtake her body. Exercise, yoga and conscious relaxation do not always work. When she feels the headache coming on, she tries to stop it with medications. Because she medicates, she has chosen to not sleep, but is more comfortable with lost sleep than with a migraine. Elizabeth accepts this lifestyle to manage the headaches, but her thoughts of the future are filled with fear related to new and potentially stressful environments and the lack of useful support in those environments. Elizabeth functions best during a migraine when someone provides her with silence, intuitive questioning, and supplying a wet wash cloth without having to be asked to do so. Elizabeth lives life to the fullest, strong and supported by her boyfriend and parents. 
Elizabeth hopes others will learn to understand that when she is sick with a headache, her lashing out is not meant to hurt their feelings, but their voice is overwhelming to her in that moment.

\section{The Story of "Zoe" \\ Participant 3 \\ Anthony Ramsey \\ Revised January 12, 2011}

Zoe began experiencing migraine's at age eleven. Because her mother experiences migraines, both of her parents have always been a strong support system for Zoe, even now at twenty-four years old. Zoe recalls living alone in another state after college. She has a vivid memory of a headache that caused so much head pressure that she thought her head would "explode". It was her mother and father who made the three hour drive to support her and just sit with her during the attack.

Today, Zoe experiences pressure in her head, sometimes even caused by the hat and sunglasses she uses to shield her eyes. Her words are "it's like a battle" when referring to the headaches. She states that she has learned to deal with the headaches over the past months by managing stress and "not taking life too seriously". However, Zoe admits that many of the people she works with "frustrates" her to a point where she could just "hit something". When her stress management strategies fail, Zoe relies on her medications to stop the migraine early. Because of allergies, Zoe's medication arsenal for preventing and aborting migraines is limited at best, but she does keep tried and true medications close by at all times. When Zoe experiences a full blown attack, she reports that she cannot concentrate; she cannot tolerate light or sound, and does not want to hear another person's voice. She now lives alone with her dog, and she feels guilty because she can't take care of him the way she would like, and she can't stand the sound of him walking across the floor. In her words, she only wants to "cry or I just want to be in my own little cocoon". She tries her best to help the dog, but she just can't do it. The world is put on hold and "it's all about me" at that point.

Like others with migraine, Zoe avoids known migraine triggers such as stress, and certain foods. She admits to "giving in" to chocolate on occasion, and suffering the consequences of her indulgence with a migraine. She tries to get regular exercise and to unwind after work by watching television with her dog. She has tried acupuncture, sees her primary care physician on a regular basis and uses the emergency room for an uncontrollable headache. Utilizing the healthcare system has left Zoe with numerous medical bills. These bills are a source of stress for Zoe, so she tries to navigate the cheapest route to relief as much as possible. Zoe is hopeful that medicine with no side effects to prevent migraines will be developed. She is willing to undergo brain surgery to stop the headaches if such procedures would help the migraines to disappear forever. Zoe's hope for a cure is strong, but so is her belief that she will never have children because she does not want to possibly pass along migraine headache to her offspring. This stance is strengthened in Zoe's statement about her own mother: "I'm like, mom, why did you do this to me?" 


\section{The Story of "Rachel" \\ Participant 4 \\ Anthony Ramsey \\ Revised January 12, 2011}

Sixty-two year-old Rachel migraine headache story began many years ago. She had experienced menstrual related migraines since she was a teenager. She never asked her doctor about the headaches, because she felt it was "silly" to waste his time with something like a headache. The headaches became worse as Rachel's life progressed, and she sought help for them just before her $50^{\text {th }}$ birthday. She was prescribed medications that provided relief for the headaches. Because of dysfunctional uterine bleeding, Rachel underwent a total hysterectomy around the same time her migraines were diagnosed and treated. The surgical menopause relieved the headaches, but she soon began to experience ocular migraines which still occur today.

Rachel states that the ocular migraine she experiences now have a distinct connection with stress and prolonged work hours. She cannot see out of one eye and cannot focus on anything except resting when the ocular migraines occur. She happily reports that over-the-counter medications and caffeine seem to relieve her ocular migraines. However, Rachel's work and life outside of work are impacted by the ocular migraine just as it was with the headaches in years past. She recalls that when she had headaches, she would often have to leave work to go home and climb into bed. Although she emphasizes she was not a bad mother for doing so, Rachel recalls bringing her small child to bed with her and hugging him tight so that he would sleep, and then she too could rest and try to rid herself of the pain.

Rachel has accepted that migraines are a part of her life. On the other hand, she does recall asking herself "why am I a woman". Although she enjoyed bearing children, she feels that having a period, engaging in the many different roles a lot of women undertake, and dealing with sever migraines is more than anyone should endure. She remembers pushing through the pain to do all that needed to be done that day. Rachel's current work position and role as a grandmother allows her the freedom to slow down or stop for a migraine, but that was not always the case. She would dread her period because she "didn't feel good anyway" at that time of the month, and a headache just made it that much worse. If she did give in to the pain and miss work, she felt judged. Rachel questions why it is okay in our society to stay home for work with the flu, but it is not okay to stay home with a migraine headache.

Rachel realizes that perhaps she could have been spared some suffering if she had discussed the headaches with her doctor much earlier in life. She feels that she could have better coped with her many different roles, especially motherhood, had she done so. Instead, she lived a life of "pushing through" the pain to do all she had to do, and be all that she had to be for everyone else in the world. 


\section{The Story of "Meredith" \\ Participant 5 \\ Anthony Ramsey \\ Revised January 12, 2011}

Meredith is twenty-seven years-old. She has experienced migraine headache for the past ten years. Meredith cannot focus when she has a migraine. In her words, she has "no will to comprehend", and prefers to retreat to a cold, dark, and quite bedroom when a migraine strikes. Meredith feels fortunate that her employer allows her the flexibility to stay at home during an attack, but at the same time, Meredith feels as if her colleagues and friends may judge her as "faking" a migraine to avoid work or an event. She feels that the migraines get in the way of a productive and substantive life. Because of the migraines, she has often felt like she ruined others joy, but she asserts that others "just don't get it" (what it's like to live with migraines). She wishes that others in her life could have just one migraine so that they would understand. Meredith defends others with migraine when they too are being judged by those without an understanding.

Meredith feels as if she has a lot of support during her headaches. Because her sister, mother and grandmother all experience migraines, she is provided with a network of care and understanding. Meredith takes prophylactic medicines now in an effort to prevent the headaches, but this was not always the case. When she was first diagnosed with migraines, she was prescribed the same prophylactic treatment as what she takes daily now. Her doctor did not explain to her at age 17 why she was taking the medicine, so she saw no value in continuing to take the medication. She now understands the reasoning for the prophylactic medicines, and accepts them as part of migraine prevention. She also utilizes abortive medications when the migraines strike. Meredith is very worried about not having these abortive medications on hand. Her fear is that her prescription will run out and she will need to navigate the often complex system of prescription attainment during a migraine attack. Because of her experiences with obtaining prescriptions when in urgent need, Meredith keeps her abortive medication in her purse, at her work, at home, and at her parent's house.

The migraines Meredith experiences are triggered by weather changes, dehydration, stress and menses. She can anticipate a migraine on the first day of her period each month, so she does not plan any presentations at work, or any other significant events which require her to be one hundred percent. Meredith avoids places where the weather is hot because heat and humidity are also triggers. Although she tries to "keep on smiling" when she is having a headache, or feels a headache coming on, Meredith longs to go home and be alone in her dark, cold and quite bed, which is the "best treatment" for Meredith's migraines. Meredith maintains that the anticipated migraine each month is much easier to deal with than the unanticipated headache. The unanticipated migraine interferes with all aspects of her life. Although she tries to hide her pain, Meredith admits she does not do a very good job concealing her anguish. "I wear my feelings right on my face...people get concerned". Meredith wants to be strong and independent, but she gives in to allow others to help her when she is out of the house and has a migraine headache. 


\section{The Story of "Mandy" \\ Participant 6 \\ Anthony Ramsey \\ Revised January 12, 2011}

"Like fingernails on a chalkboard". These are the words Mandy, age 43, used to describe the sound of another person's voice during her migraine headache. Mandy has lived with migraine headache since age 13 . She goes on to describe migraines as a debilitating illness that prevents her from moving, drowns the desire to interact with others, makes light unbearable and drives her to a cold, dark bed. In her bed, her hearing seems too heightened with the migraine and each sound makes intensifies the pain. A dripping faucet or ticking clocks are unbearable as she tries to sleep and get some relief from the all-encompassing pain in her head. Mandy, a single mother of one, is thankful that her 16 year old son brings her a cold wash cloth, but she feels that it is she who is supposed to be the caregiver. Mandy concedes that when she has a migraine, she can't take care of herself or anyone else.

Mandy avoided known migraine triggers since the onset of migraine headache. Even when she avoids triggers as much as possible, physical and mental stress creeps in to cause an unanticipated headache. These headaches have caused Mandy to miss movies with her son, and many days at work. Even when the headache subsides, Mandy maintains that it takes a couple of days to recover from the migraine. She likened the migraine experience to a person with the flu, sick in bed, and not able to eat or drink. The person with the flu will need a couple of days to regain their strength, much like a woman with a migraine headache. Mandy reports that she does not sleep when she is in bed with a migraine, adding to her flu-like description of migraine headache.

Mandy goes on to describe herself as "OCD" in regard to her job and homemaking. As a person who expects perfection from herself, missing work and other life events serve as a source of stress for Mandy. This stress builds and could possibly lead to another migraine headache; however, Mandy happily reports that after 30 years she has found a migraine prophylactic medication that seems to be keeping her migraine free. This served as a sparkle of hope in Mandy's future, as did the hope for a complete migraine cure with hysterectomy. The Neurologist stopped Mandy's medication after the surgery, but the headaches resumed. Because she can't stop the medications and because Mandy's mother is 61 years-old with active migraines, Mandy reports "I am just kind of resigned to this is the way it's going to be. Suck it up and live with it". She wishes others could understand that migraines are overwhelming and not something that goes away like the flu. 


\section{The Story of "Brittany" \\ Participant 7 \\ Anthony Ramsey \\ Revised January 12, 2011}

When Brittany was 13 years old, she started having migraine headache, just like the other women in her immediate family, including her mother. She remembers very well that her mom, a school teacher, would insist that she attend school, even if all she did was sit there. Brittany recalls being in a daze at school because of the migraines. She couldn't focus, and she would sometimes sleep in class. Today, Brittany pushes through in a similar way, not giving into the pain until absolutely necessary.

Brittany is determined to become a school teacher. She works full-time while completing an internship. She describes her life as "tortured" when she speaks of migraine headache. This torture is caused by the unknowing related to when the migraine will strike, as well as the pounding pain in her head at the moment of migraines impact. Further torture is invoked by the nausea, photophobia, and the annoyance of sound which accompanies her headaches. Brittany has struggled to find a preventative medication to decrease the frequency of the migraines. She thinks that her current pills are helping her more than any before, but even with the medication, she experiences headaches. Her neck begins to ache, and a pain sets in above her eyes. As the headache becomes more intense, she wishes for a head cold, or any mild illness other than a migraine. She can't move because of the pain. Sleep does not help. Brittany does not want to focus on anything requiring thought. Brittany requires a couple of days to recover from the headache and return to "normal".

Brittany feels as if others at work and school do not understand the migraine process. She feels judged for missing work, and is frustrated that she cannot accomplish what she intended to do on those days. She believes this frustration leads to more migraines. Even when others do understand, Brittany feels guilty for missing events or for talking rudely because of her headache. She has recently spent a lot of time thinking about the impact of migraines may have on her future career as a teacher and librarian. Her reality is that the job will not accommodate her "migraine schedule". Brittany does not want others to see her as "sick" and has been thinking a lot about how this will impact her own children if and when she decides to have children. She doesn't want her kids to have to always be quite when she has a headache, or miss out on time with her kids because of the headache. This is partly due to Brittany's own experiences as a child with a mother who had migraines. Brittany wants control over the headaches, and wishes that other people could see just how uncontrollable migraine headache are for her each time they occur. 


\section{The Story of "Sue" \\ Participant 8 \\ Anthony Ramsey \\ Revised January 12, 2011}

Fifty-four year-old Sue describes a migraine headache as a "freight train coming through" her head. During the migraine, Sue is very sensitive to light and sound. She describes others voices as "echoing through my head" and that it is much like someone turning up the volume of a stereo. Sue has been to the emergency room on many occasions seeking treatment. She was most thankful when the nurses would place her in a dark, quite room. Sue's headaches require her to take care of herself only. This is not as difficult to do now that her children are grown, but during the children's early years, her husband carried the burden of childcare when she was sick with a headache. Sue feels that the migraine headache drains her body, making it so that she cannot concentrate. She is exhausted after an episode and needs a few days to recover. She is also concerned that she cannot conceal her pain: "people can always tell when I had one because of my face, my eyes.... You just feel totally drained".

Sue's life can be described with many medical visits and constantly being on guard for the next headache. The unpredictability of the migraine attack creates a sense of uneasiness for Sue. Even with all of her experience and learning which triggers to avoid, Sue still searches for possible triggers. For example, she recently discovered with trial and error that cinnamon is a definite trigger for her migraines. Sue is vigilant in avoiding any of known triggers "like I told you before, knowing that chocolate starts the migraine or contributes to the migraine, I would much rather do without the chocolate than have the migraine". Sue wishes that others who have migraines would embrace this notion of avoiding known triggers. Additionally, Sue hopes that more information will become available regarding migraine management so that she and other people will not have to suffer as much. 


\section{Appendix $J$}

Grouping of Thematic Statements and Structures of Meaning

Participants 1-8, 106 Statements from Reconstructed Stories

\section{When first experienced}

Living with migraine headache is recalling the significant experience that reshaped life.

- A thirty-three year old single mother who began having migraines at age sixteen.

- Diagnosed at age 3, and is 20 years old now

- 24 years old and has been experiencing migraines since age 11 .

- 62 years old and began having migraines as a teenager.

- Her headaches left with a hysterectomy, but ocular migraines began occurring.

- 27 years old and has had migraines for 10 years.

- 43 years old, a single mother, and has lived with migraines for 30 years.

- She started having migraine headache at age 13 , just like the other women in her family.

\section{View of self}

Living with migraine headache is experiencing self as vulnerable, with unmet expectations, unfulfilled relationships and regrets.

- Perfection is a self-expectation.

- She feels she is not the perfect Mom because of migraine headache which cause her to miss out on time spent with her children.

- She wants to be seen as someone who is well.

- Migraines are viewed by her as something that is a part of her, not a disability.

- She accepts that migraines are a part of her life.

- She reports "I am just kind of resigned to this is the way it's going to be. Suck it up and live with it"

- She questions why she is a woman and had to endure monthly periods, headaches, and the many roles that women must take on.

- She now could have decreased her suffering if she had sought help for the headaches earlier in her life.

- She describes herself as "OCD", a perfectionist at work and home.

- Migraine headache invoke unwanted sympathy from others when they see her puffy eyes.

- Important childhood events were missed.

- She thinks healthcare providers see her as "tired and whiny".

- She does not want children because she may pass migraine headache to them.

- She is considering not having children who would be subject to watching her live with migraines. 


\section{Headache Experience}

Living with migraine headache is being overcome by unrelenting, torturous pain magnified by intrusion from the outside world.

- She can't drive, focus her mind, or go out with a migraine

- The medicine keeps her awake.

- She has a memory of a headache that cause so much pressure that she thought her head would explode.

- She cannot concentrate, tolerate light or sound, or tolerate a voice when she has a migraine.

- Ocular migraines cause blindness in one eye, are stress induced, and are relieved with caffeine and over-the-counter medications.

- She has "no will to comprehend" when a migraine strikes.

- She does not do a good job of concealing her anguish. "I wear my feelings right on my face... people get concerned".

- "Like fingernails on a chalkboard" are the words she used to describe the sound of another's voice when she has a headache.

- She experiences light sensitivity, nausea, and sensitivity to sound during the migraine process.

- She cannot focus on anything requiring thought.

- 54 year-old woman who describes migraines as a "freight train coming through" her head.

- She states that voices and sound are "echoing through my head" during the migraine.

- She cannot concentrate. She is exhausted and needs a few days to recover from the migraine process.

- The pain begins as a neck ache and slowly moves to her head when a migraine is emerging.

\section{Moving through the headache}

Living with migraine headache is pushing through to hold self together to do what needs to be done, in spite of torturous pain.

Living with migraine headache is surrendering to the compelling call to focus on self in order to relieve the torturous pain.

- The cocoon of a bed, covers over the head, and complete silence allows her to lay without focusing on thought.

- Because of the need to ensure that her children are safe and their basic needs are met, she now cocoon's with one eye open. 
- Once the migraine process subsides, she can mend fences, redo chores, and spend time with her children.

- She waits out her headaches.

- Her mother is best at caring for her because she lets her be, and knows when to speak.

- Her mother has migraines, allowing both her parents the experience to provide her with support.

- She cannot care for herself or her dog when she has a headache.

- "It's all about me" when the migraine occurs.

- She went to bed when she had headaches, sometimes hugging her son tightly so that he would sleep, allowing her to rest too.

- She pushed through to do all that was required of her as a woman.

- She prefers to retreat to a cold, dark and quite bed.

- All of the women in her immediate family have migraines and provide support for each other.

- She tries to "keep on smiling" when in pain.

- She just wants to push through the day and go home when she has a headache.

- She is too busy to stop for migraines.

- Her bed is the best treatment for her headaches.

- She wants to be strong and independent, but gives in to allow others to help her.

- When she has a migraine, she can't care for herself or anyone else.

- This woman prefers a cold, dark bed when migraines strike.

- She pushes through the pain as much as possible, not giving in until absolutely necessary.

- Her headaches require her to take care of herself only.

- She describes migraines as a debilitating illness that prevents her from moving.

- Mother has migraines and knows exactly what to do.

- She never asked about medications for the headache for many years because she felt it was silly to waste the doctor's time.

- Her son brings her a wash cloth, but she feels like she should be the caregiver.

- This woman took charge of her medications at age 13 because she wanted immediate treatment and to avoid pity from the school nurse.

- She medicates herself early when a migraine is emerging.

- Medications will sometimes stop the headache early in the process, so she keeps these medicines close by.

- This woman worries about running out of medications, and keeps abortive medications in her purse, at work, at home, and at her parent's house.

- Thinking that the migraines would subside, she stopped her medication after a hysterectomy, but the migraines returned.

- Exercise and television allow her to relax.

- She uses her primary care provider, as well as the emergency room as resources for migraine prevention and treatment.

- This woman is hopeful for a migraine medication without side effects.

- She is willing to undergo surgery to stop the headaches. 
- She refused to take preventive medications until she understood why she was taking them.

- Medical bills are a source of anxiety.

\section{Getting through the day}

Living with migraine headache is making the most of pain-free time to get on with life and navigating the aftermath of the headache experience.

Living with migraine headache is being on guard against an unpredictable attack and yet hopeful that it is possible to outsmart the next attack.

- Unanticipated migraines cause her to miss work and events, causing her anxiety and disappointment.

- Unanticipated migraines interfere with all aspects of her life.

- Unanticipated headaches have caused her to miss movies with her son, and many days at work.

- She is frustrated that she cannot accomplish what she intended that day.

- The unpredictability of the migraine attack creates uneasiness for her.

- She feels migraines get in the way of a productive life.

- This woman expects a migraine on the first day of her period each month, and does not plan anything requiring thought and concentration.

- She describes her life as "torture" because of the headaches themselves, and the not knowing of when they will strike.

- She is vigilant in identifying and avoiding migraine triggers.

- Her friends are slowly realizing her fate when a migraine strikes.

- She becomes so frustrated with others that she could hit something.

- Menstrual migraines can be predicted; the most troublesome migraines are those that are unanticipated.

- Exercise, relaxation, avoiding caffeine and avoiding known food triggers are part of her migraine prevention plan.

- Stress and anxiety, cold weather, and lack of sleep induce migraines

- Known triggers for her are stress and certain foods, but she is willing to risk a headache in order to indulge in a piece of chocolate.

- Migraine triggers for her are stress, menses, weather changes, and dehydration.

- Because migraine is classified as a chronic illness, she cannot secure an immediate appointment with her provider when she has a migraine.

- She avoids stress as much as possible, engaging in exercise, yoga and conscious relaxation as much as possible.

- Managing stress helps her to deal with and prevent migraines.

- She wishes for a head cold or any other mild illness instead of the headache.

- She wants control over her headaches. 
- She wishes others would embrace the notion of avoiding triggers.

- She felt judged when she missed work because of migraines.

- This woman feels judged, or that others think she is faking the migraine when she misses work due to a headache.

- She asserts that others "just don't get it" when she speaks about migraines.

- She feels judged for missing work.

- She wishes others could see how uncontrollable migraines are when they occur.

- She maintains that because of the lack of food, drink, and lack of sleep, recovering from a migraine takes a couple of days, much like it is with the flu.

- She requires a couple of days to return to "normal" after the pain leaves

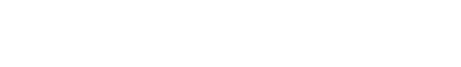

